\title{
Synaptic Activity Unmasks Dopamine D2 Receptor Modulation of a Specific Class of Layer V Pyramidal Neurons in Prefrontal Cortex
}

\author{
Steven Gee, ${ }^{1 *}$ Ian Ellwood, ${ }^{1 *}$ Tosha Patel, ${ }^{1}$ Francisco Luongo, ${ }^{1}$ Karl Deisseroth,${ }^{2}$ and Vikaas S. Sohal ${ }^{1}$ \\ ${ }^{1}$ Department of Psychiatry, University of California, San Francisco, San Francisco, California 94143 and ${ }^{2}$ Departments of Bioengineering and of Psychiatry \\ and Behavioral Sciences, Stanford University, Stanford, California 94305-2004
}

\begin{abstract}
Dopamine D2 receptors (D2Rs) play a major role in the function of the prefrontal cortex (PFC), and may contribute to prefrontal dysfunction in conditions such as schizophrenia. Here we report that in mouse PFC, D2Rs are selectively expressed by a subtype of layer V pyramidal neurons that have thick apical tufts, prominent h-current, and subcortical projections. Within this subpopulation, the D2R agonist quinpirole elicits a novel afterdepolarization that generates voltage fluctuations and spiking for hundreds of milliseconds. Surprisingly, this afterdepolarization is masked in quiescent brain slices, but is readily unmasked by physiologic levels of synaptic input which activate NMDA receptors, possibly explaining why this phenomenon has not been reported previously. Notably, we could still elicit this afterdepolarization for some time after the cessation of synaptic stimulation. In addition to NMDA receptors, the quinpirole-induced afterdepolarization also depended on L-type $\mathrm{Ca}^{2+}$ channels and was blocked by the selective L-type antagonist nimodipine. To confirm that D2Rs can elicit this afterdepolarization by enhancing $\mathrm{Ca}^{2+}$ (and $\mathrm{Ca}^{2+}$-dependent) currents, we measured whole-cell Ca ${ }^{2+}$ potentials that occur after blocking $\mathrm{Na}^{+}$and $\mathrm{K}^{+}$channels, and found quinpirole enhanced these potentials, while the selective D2R antagonist sulpiride had the opposite effect. Thus, D2Rs can elicit a $\mathrm{Ca}^{2+}$-channel-dependent afterdepolarization that powerfully modulates activity in specific prefrontal neurons. Through this mechanism, D2Rs might enhance outputs to subcortical structures, contribute to rewardrelated persistent firing, or increase the level of noise in prefrontal circuits.
\end{abstract}

\section{Introduction}

Dopamine plays a critical role in prefrontal cortex (PFC). First, depleting prefrontal dopamine impairs working memory in monkeys (Brozoski et al., 1979), and genetic variations in prefrontal dopamine catabolism affect both PFC-dependent executive function and prefrontal physiology in humans (Egan et al., 2001). Second, imbalanced prefrontal dopaminergic signaling may contribute to disorders including schizophrenia (Arnsten and Goldman-Rakic, 1998; Winterer and Weinberger, 2004; Kellendonk et al., 2006). Third, reward signals

Received Nov. 18, 2011; revised Feb. 22, 2012; accepted Feb. 26, 2012.

Author contributions: S.G., I.E., K.D., and V.S.S. designed research; S.G., I.E., T.P., and F.L. performed research; S.G., I.E., and V.S.S. analyzed data; V.S.S. wrote the paper.

K.D. is supported by the president and provost of Stanford University, and by Howard Hughes Medical Institute, California Institute for Regenerative Medicine, National Science Foundation, National Institute of Mental Health (NIMH), National Institute on Drug Abuse, and the McKnight, Coulter, Kinetics, and Keck Foundations. V.S.S. is supported by the Staglin Family and International Mental Health Research Organization, R00 MH085946-02 from NIMH, the Simons Foundation for Autism Research, a Steve and Connie Lieber/National Alliance for Research on Schizophrenia and Depression Young Investigator Award, and a Sloan Research Fellowship. We acknowledge the advice and suggestions of Professors Robert C. Malenka, John L. Rubenstein, and John R. Huguenard on earlier versions of this work.

*S.G. and I.E. contributed equally to this work.

Stanford University has a pending patent application based on this work, which includes K.D. and V.S.S. as inventors.

Correspondence should be addressed to Vikaas S. Sohal, Department of Psychiatry, Box 0984-IRE, 401 Parnassus Avenue, University of California, San Francisco, San Francisco, California 94143. E-mail: vikaas.sohal@ucsf.edu.

DOI:10.1523/JNEUROSCI.5835-11.2012

Copyright $\odot 2012$ the authors $\quad 0270-6474 / 12 / 324959-13 \$ 15.00 / 0$ are typically mediated by dopamine (Schultz, 2007), and the past history of reward modulates prefrontal neuron excitability (Bernacchia et al., 2011) and can trigger persistent firing (Histed et al., 2009).

Prefrontal dopamine D2 receptors (D2Rs) play critical roles in cognition. Infusion of D2 agonists and antagonists into PFC modulates working memory and set-shifting in rodents (Druzin et al., 2000; Floresco et al., 2006; St Onge et al., 2011). Systemic administration of D2 agonists in nonhuman primates affects working memory and elicits "hallucinatorylike" behaviors (Arnsten et al., 1995). In nonhuman primates, prefrontal D2Rs are specifically necessary for neural activity associated with memory-guided saccades (Wang et al., 2004). Consistent with these animal studies, genetic variation in D2Rs modulates prefrontal activity and working memory in humans (Zhang et al., 2007).

Given that all antipsychotics block D2Rs, and that prefrontal D2Rs play a major role in tasks that are disrupted in schizophrenia, a major hypothesis is that excessive D2R activation contributes to prefrontal dysfunction in schizophrenia (Winterer and Weinberger, 2004; Durstewitz and Seamans, 2008). Prefrontal D2Rs may also contribute to Tourette syndrome and bipolar disorder (Simonic et al., 1998; Minzer et al., 2004; Yoon et al., 2007; Minton et al., 2009; Steeves et al., 2010). Thus, D2Rs play a major role in both normal and pathological prefrontal function. Specifically, D2Rs may increase the variability of PFC activity (Winterer and Weinberger, 2004; Durstewitz and Seamans, 
2008). Under normal conditions, such variability could facilitate adaptation to a changing environment (Durstewitz et al., 2010; St Onge et al., 2011). However, excessive or imbalanced D2R activation might produce pathological variability that contributes to "prefrontal noise" and cognitive dysfunction in schizophrenia (Winterer and Weinberger, 2004).

We focused on layer $\mathrm{V}$ pyramidal neurons in PFC because these neurons contain most prefrontal D2Rs (Lidow et al., 1998; Santana et al., 2009). A few studies have described ways that D2Rs enhance (Wang and Goldman-Rakic, 2004) or suppress (Gulledge and Jaffe, 1998; Tseng and O'Donnell, 2004) excitability in these neurons. A possibly related observation is that dopamine profoundly depolarizes frontal cortex pyramidal neurons in vivo (Bernardi et al., 1982). Nevertheless, specific mechanisms for D2R modulation of layer $\mathrm{V}$ pyramidal neurons in PFC remain elusive.

Here we report two major results about D2Rs in layer $\mathrm{V}$ of PFC. First, D2Rs are not uniformly distributed across layer V cell populations, but rather restricted to a specific subpopulation of layer $\mathrm{V}$ pyramidal neurons with thick apical tufts, prominent h-current, and subcortical projections. Second, in these neurons, D2Rs elicit a novel afterdepolarization that depends on NMDA receptors and L-type calcium channels, and can drive spiking for hundreds of milliseconds.

\section{Materials and Methods}

All experiments were conducted in accordance with procedures established by the Administrative Panels on Laboratory Animal Care at the University of California, San Francisco.

Slice preparation. Slice preparation and intracellular recording followed our published protocol (Sohal and Huguenard, 2005). We cut 250 $\mu \mathrm{m}$ coronal slices from 6- to 10-week-old mice of either sex. Specifically, all electrophysiological experiments showing the quinpirole-induced afterdepolarization were from 9- to 10 -week-old mice, except for 4/7 perforated patch experiments, which were from 6- to 7-week-old mice. We used the following mouse lines: wild-type C57BL/6 mice (Charles River), Drd1::EGFP (line S118; www.gensat.org), Drd1::Cre (line EY262; www. gensat.org), Drd2::EGFP (www.gensat.org), and Drd2::Cre (line ER44; www.gensat.org). We secured the slice by placing a harp along the midline between the two hemispheres.

Intracellular recording. We obtained somatic whole-cell patch recordings from visually identified pyramidal cells in layer $\mathrm{V}$ of infralimbic or prelimbic cortex using differential contrast video microscopy on an upright microscope (BX51WI; Olympus). Recordings were made using a Multiclamp 700A (Molecular Devices). Except when otherwise noted, patch electrodes (tip resistance $=2-6 \mathrm{MOhms}$ ) were filled with the following (in $\mathrm{mm}$ ): $130 \mathrm{~K}$-gluconate, $10 \mathrm{KCl}, 10 \mathrm{HEPES}, 10 \mathrm{EGTA}, 2$ $\mathrm{MgCl}, 2 \mathrm{MgATP}$, and $0.3 \mathrm{NaGTP}$ (pH adjusted to 7.3 with $\mathrm{KOH}$ ). For perforated patch recordings, the pipette solution included $0.02 \mathrm{mg} / \mathrm{ml}$ gramicidin D. ACSF contained the following (in $\mathrm{mm}$ ): $126 \mathrm{NaCl}, 26$ $\mathrm{NaHCO}_{3}, 2.5 \mathrm{KCl}, 1.25 \mathrm{NaH}_{2} \mathrm{PO}_{4}, 1 \mathrm{MgCl}_{2}, 2 \mathrm{CaCl}$, and 10 glucose. In experiments that used tetraethylammonium chloride (TEA), the amount of $\mathrm{NaCl}$ was decreased by a corresponding amount $(30 \mathrm{~mm})$ to maintain the osmolarity of the extracellular solution. All recordings were at $32.5 \pm$ $1^{\circ} \mathrm{C}$. Series resistance was usually $10-20 \mathrm{M} \Omega$, and experiments were discontinued above $30 \mathrm{M} \Omega$.

Injection of virus for ChR2 or EYFP expression. For Cre-dependent expression of ChR2 or EFYP, we used a previously described adenoassociated virus (AAV) vector that drives Cre-dependent expression of a ChR2-EFYP fusion protein (Sohal et al., 2009). In other cases, we expressed ChR2-EFYP in pyramidal neurons using a previously described AAV vector that contains a gene encoding ChR2-EYFP under control of the promoter for CaMKII $\alpha$ (Yizhar et al., 2011). In each case, we injected $0.5-0.75 \mu \mathrm{l}$ of virus following previously described procedures (Sohal et al., 2009). For experiments in which we recorded from ChR2-negative neurons while stimulating ChR2-positive axons, we injected virus into the contralateral medial PFC (mPFC), and verified that we observed fluorescent soma on the injected side, but not on the contralateral side (which was the location for recording). In $3 / 5$ of these experiments, we drove expression using the Credependent virus in Drd1::Cre mice, while in the other 2/5 experiments we injected the virus carrying the CaMKII $\alpha$ promoter into wild-type mice. We waited at least 3-4 weeks after virus injection before preparing brain slices. Coordinates for injection into $\mathrm{MPFC}$ were (in millimeters relative to bregma): 1.7 anterior-posterior (AP), 0.3 mediolateral (ML), and -2.75 dorsoventral (DV).

Injection of retrogradely transported microspheres for projection targeting experiments. Procedures for injection of these microspheres were similar to those for virus injection. We waited at least $48 \mathrm{~h}$ after each injection before preparing brain slices. Coordinates for $\mathrm{mPFC}$ injections were the same as for virus injections. For injections into mediodorsal (MD) thalamus, coordinates were (in millimeters relative to bregma): $-1.7 \mathrm{AP}, 0.3$ $\mathrm{ML}$, and $-3.5 \mathrm{DV}$. For each experiment, we verified that microspheres were present in the correct target (MD thalamus or $\mathrm{mPFC}$ ). For injections into MD thalamus we specifically verified that microspheres were not present in nearby structures (e.g., striatum).

Drug application. For electrophysiology, all drugs were dissolved in water (quinpirole, NMDA, DL-AP5, apamin, bicuculline methiodide, and TEA) or dimethylsulfoxide (sulpiride, and nimodipine) before being diluted in ACSF, except for tetrodotoxin (TTX) which was dissolved in a pH 4.8 citrate buffer. (Throughout the text, AP5 refers to DL-AP5, bicuculline refers to bicuculline methiodide, and sulpiride refers to (-)sulpiride).

ChR2 stimulation. We stimulated ChR2 in pyramidal neurons using flashes of light generated by a Lambda DG-4 high-speed optical switch with a 300W Xenon lamp, and an excitation filter set centered around $470 \mathrm{~nm}$, delivered to the slice through a $40 \times$ objective (Olympus). Illumination was delivered across a full high-power $(40 \times)$ field.

Biocytin fills, morphological analysis, and confocal imaging. For experiments in which we studied cell morphology, the intracellular solution contained $0.3 \%$ biocytin. Cells filled with biocytin were fixed overnight in a buffered solution containing $4 \%$ paraformaldehyde. To visualize filled cells, we washed fixed slices in $0.1 \mathrm{Mr}$ PBS, then incubated for 40 min in PBS with 1-2\% Triton X-100, before incubating for $1 \mathrm{~h}$ in PBS with $0.5 \%$ Triton X-100 and Texas Red Avidin D or Fluorescein Avidin D (1:500). Before mounting the slice, we washed it with PBS again. We measured the width of the apical dendritic shaft $5 \mu \mathrm{m}$ above the soma. To visualize fluorescent cells, we followed a similar protocol omitting incubation with Avidin D. All imaging was performed on a Zeiss LSM510.

Statistical analysis. We used Student's $t$ tests to compare pairs of groups, unless there were repeated measurements or unpaired observations, in which case we used ANOVA. To compare time constants for $90 \%$ decay of the quinpirole-induced afterdepolarization, we first logtransformed these time constants, because their distributions in quinpirole were highly skewed and non-Gaussian. Error bars indicate \pm 1 SEM unless otherwise specified.

\section{Results}

\section{$H$-current identifies a subpopulation of layer $V$ pyramidal neurons in the PFC that express D2Rs}

Initially, we studied whether D2Rs are selectively expressed in previously identified subpopulations of layer $\mathrm{V}$ pyramidal neurons. Previous studies have classified layer V pyramidal neurons from somatosensory or frontal cortex based on projection targeting or apical tuft morphology, and found that these characteristics are strongly correlated (Morishima and Kawaguchi, 2006; Hattox and Nelson, 2007). Specifically, layer V pyramidal neurons that project to the thalamus or brainstem have apical dendrites with wider arborizations, thicker shafts, and a greater number of primary branches, than do apical dendrites originating from layer $\mathrm{V}$ pyramidal neurons that project to contralateral cortex (CC) and/or striatum. This suggests that layer $\mathrm{V}$ pyramidal 
A

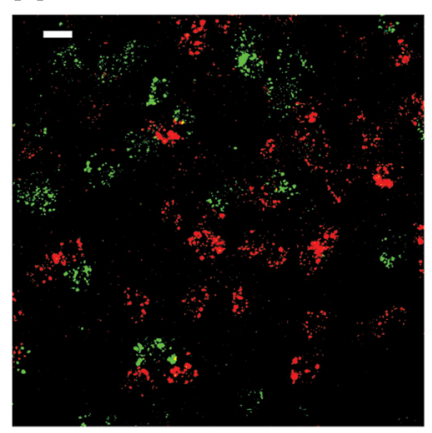

B

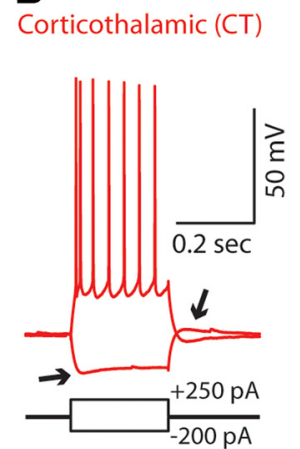

Corticocortical (CC)

C

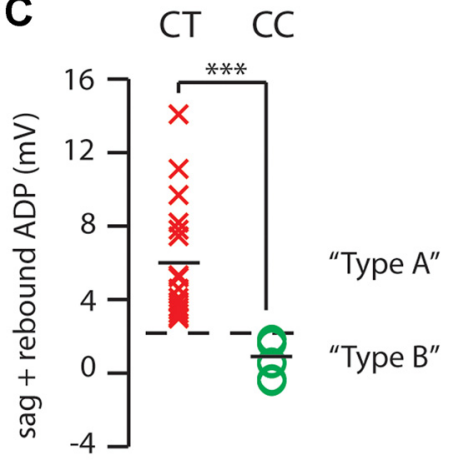

D

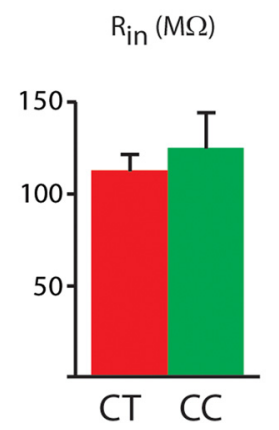

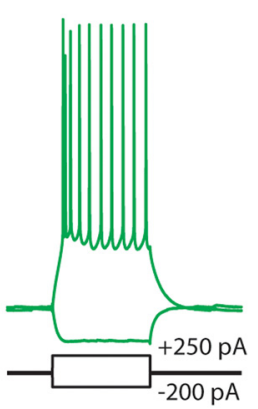

$\mathrm{V}_{\text {rest }}(\mathrm{mV})$

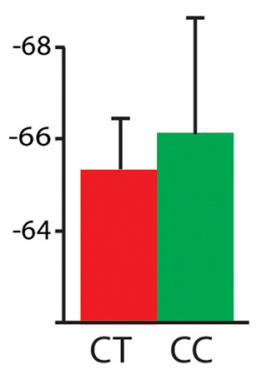

Figure 1. H-current distinguishes two populations of layer V pyramidal neurons that differ in their projection targets. $\boldsymbol{A}$, High-power confocal image of layer V of mPFC showing the distribution of fluorescently labeled retrogradely transported microspheres within individual neurons. Microspheres were injected into MD thalamus (red) or the contralateral PFC (green). Scale bar, $10 \mu \mathrm{m}$. B , Sample recordings from corticothalamic (CT) or corticocortical (CC) pyramidal neurons identified using retogradely transported microspheres showing responses to hyperpolarizing or depolarizing current injection. Note the voltage sag and rebound afterdepolarization in response to hyperpolarizing current injection that is visible in the CT neuron but not the CC neuron (arrows). C, The amount of h-current, measured as the sum of the voltage sag and rebound afterdepolarization in response to hyperpolarizing current pulses, in CT $(n=18)$ and CC neurons $(n=8)$. Thick horizontal bars indicate the means of each distribution, and the dotted line indicates a threshold that unambiguously separates the two nonoverlapping distributions. $\boldsymbol{D}$, Input resistances $\left(\mathrm{R}_{\text {in }}\right)$ and resting membrane potentials $\left(\mathrm{V}_{\text {rest }}\right)$ for $\mathrm{CT}$ and $\mathrm{CC}$ neurons. ${ }^{* *} p<0.001$.

neurons in neocortex can be divided into at least two subpopulations, "thick-tufted" neurons that project to thalamus or brainstem, and "thin-tufted" neurons that project to striatum or CC. Notably, excitatory and inhibitory connectivity differs between these subpopulations (Wang et al., 2006; Otsuka and Kawaguchi, 2008; Brown and Hestrin, 2009). A recent study found that in prefrontal layer $\mathrm{V}$ pyramidal neurons that project to $\mathrm{CC}$ or brainstem, levels of the hyperpolarization-activated cyclic nucleotide-gated cation h-current $\left(I_{\mathrm{h}}\right)$ are low or high, respectively (Dembrow et al., 2010). An analogous relationship holds in motor cortex (Sheets et al., 2011).

Given these previous findings, we first sought to confirm that we could use h-current to classify neurons that have different projection targeting. If prefrontal corticothalamic (CT) and corticopontine neurons have similar properties, since they are both thick-tufted, then the level of h-current in CT neurons should be greater than that in CC neurons. Indeed, we found that h-current could be used to reliably distinguish CT and CC neurons in layer $\mathrm{V}$ of mPFC (Fig. 1A-D). To identify CT or CC neurons, we injected retrogradely transported fluorescently labeled latex microspheres (Retrobeads; Lumafluor) into the ipsilateral MD thalamus or the contralateral PFC. As illustrated in Figure $1 \mathrm{~A}, \mathrm{CT}$ and CC neurons were distinct populations. We made whole-cell patch-clamp recordings from identified CT or CC neurons in layer V of the mPFC. Although CT and CC neurons had similar resting membrane potentials and input resistances (Fig. 1D), they had significantly different levels of h-current (measured as the sum of the voltage sag and rebound depolarization in response to a hyperpolarizing current pulse) (Fig. $1 B, C ; p<0.01 ; n=18$ and 8 $\mathrm{CT}$ and CC neurons, respectively). In fact, the distributions of h-current from CT and CC neurons were completely nonoverlapping (Fig. 1C).

Thus, we could define a threshold level of h-current that would unambiguously separate CT and CC neurons. We refer to layer $\mathrm{V}$ pyramidal neurons above this threshold as "type A" neurons, and those below this threshold as "type B neurons." Based on the studies outlined above, we would predict that type A neurons (more h-current) would be thick-tufted, whereas type B neurons (minimal h-current) should be thin-tufted. Indeed, after filling layer $\mathrm{V}$ pyramidal neurons in $\mathrm{MPFC}$ with biocytin and visualizing them via confocal microscopy (Fig. 2A), we found that type A neurons $(n=4)$ had a greater number of primary branches $(p<0.05)$ and wider apical shafts $(p<0.05)$ than type B neurons $(n=4)$ (Fig. $2 B$ ). Thus, consistent with previous studies, the level of hcurrent differentiates two subpopulations of layer $\mathrm{V}$ pyramidal neurons that project to different targets and have different apical tuft morphologies.

Next, we asked whether D2Rs are selectively expressed within these two subpopulations of layer $\mathrm{V}$ pyramidal neurons in the PFC. To answer this question, we recorded from visually identified neurons expressing fluorescent proteins under control of promoters for D1Rs or D2Rs (Fig. 3A). Specifically, we recorded from fluorescent neurons in Drd1::EGFP transgenic mice $(n=4)$ (line S118), Drd1::Cre transgenic mice (line EY262) injected with virus containing a Cre-dependent construct for ChR2-EYFP (Sohal et al., 2009) $(n=6)$, Drd2::EGFP transgenic mice $(n=7)$, or Drd2::Cre transgenic mice (line ER44) injected with AAV containing a Cre-dependent construct for ChR2-YFP $(n=7)$. These transgenic mice have been widely used to study D1R- and D2Rexpressing neurons in the striatum (Gong et al., 2003; Lobo et al., 2006; Kravitz et al., 2010), and this AAV drives EYFP expression that is highly specific for Cre-expressing neurons (Sohal et al., 2009). We found that all of the presumed D2R-expressing neurons (fluorescent neurons from Drd2::EGFP or Drd2::Cre mice) were "type A," i.e., had a level of h-current current above the threshold that separates CT and CC neurons, whereas presumed D1R-expressing neurons included both type A and type B neurons (Fig. 3B).

Of course, other subpopulations of layer $\mathrm{V}$ pyramidal neurons might also express D2Rs, but not be labeled by either transgenic line we used. We identified D2R-expressing neurons using two distinct transgenic lines to minimize this possibility. The following experiments provide additional confirmation for our finding that D2R expression is restricted to a specific subpopulation of layer $\mathrm{V}$ neurons, by showing 
A

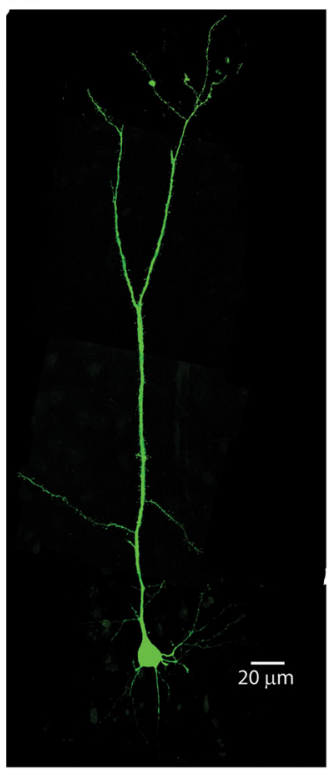

type A, "thick tufted"

B

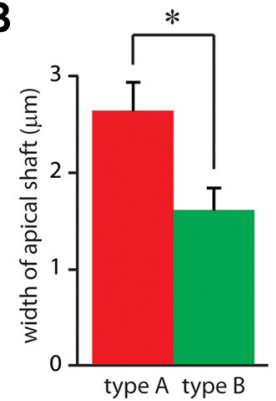

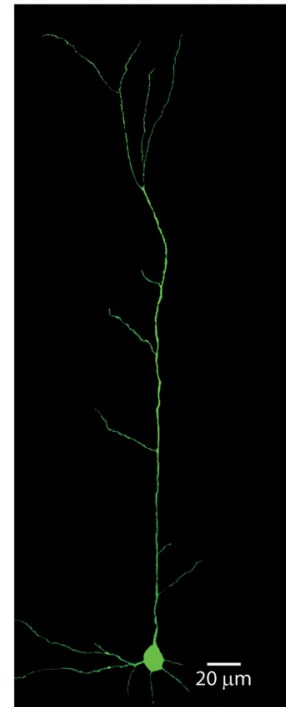

type $B$, "thin tufted"
A

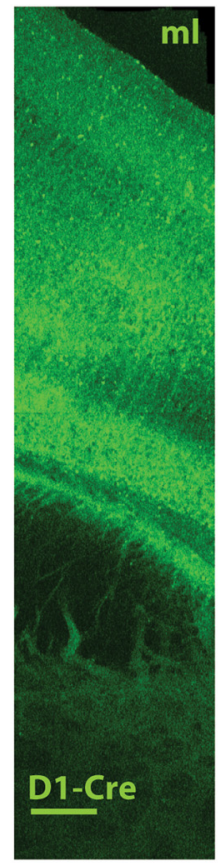

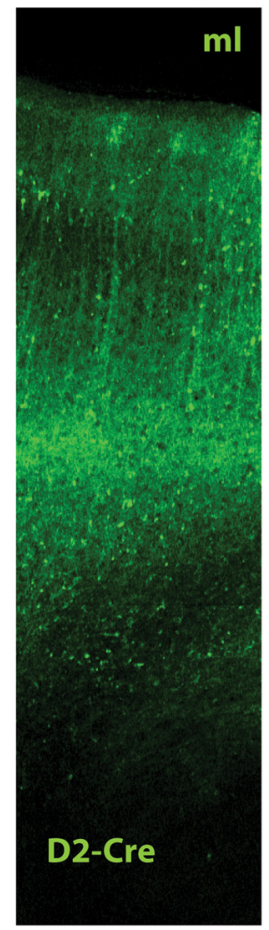

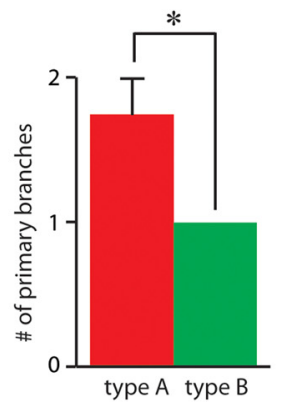

Figure 2. Type $A$ and $B$ pyramidal neurons have different morphologies. $\boldsymbol{A}$, Confocal images of representative neurons in which the amount of h-current falls either above ("type $A$," left) or below ("type B," right) the threshold in Fig. 1 C. B, Type A and B neurons differ in the widths of the shafts of their apical dendrites (left) and in the number of primary branches of their apical dendrites (right) ( $n=4$ neurons in each group).

that activating D2Rs elicits a novel cellular effect that is also restricted to this same subpopulation.

\section{Synaptic activity unmasks a quinpirole-induced afterdepolarization in type A neurons}

We measured effects of D2R activation in type A and B neurons, and surprisingly, at baseline, the $\mathrm{D} 2 \mathrm{R}$ agonist quinpirole had minimal effects on the responses of type A neurons to depolarizing current pulses (300-400 pA, 250-500 ms; Fig. $4 B-D$, left). However, when these current pulses were preceded by optogenetic stimulation of excitatory synapses in layer $\mathrm{V}$, quinpirole dramatically altered the responses of these neurons to depolarizing current. Specifically, under these conditions, quinpirole (5-20 $\mu \mathrm{M}$ ) elicited a prominent afterdepolarization in 12/12 type A neurons (Fig. 4C, middle and right; Fig. $4 E, F)$. This afterdepolarization could generate spikes and extend for up to several seconds after the end of the current pulse (Fig. $4 F$ ). In addition to this afterdepolarization, quinpirole caused a progressive decrease in spike height during the current pulse (Fig. 4C-F). Despite eliciting this dramatic afterdepolarization, both $5 \mu \mathrm{M}(-)$ quinpirole and $20 \mu \mathrm{M}$ $( \pm)$ quinpirole had minimal effects on the resting membrane potential ( $5 \mu \mathrm{M}$ : control $\mathrm{V}_{\text {rest }}=-61.7 \pm 1.4 \mathrm{mV}$, quinpirole

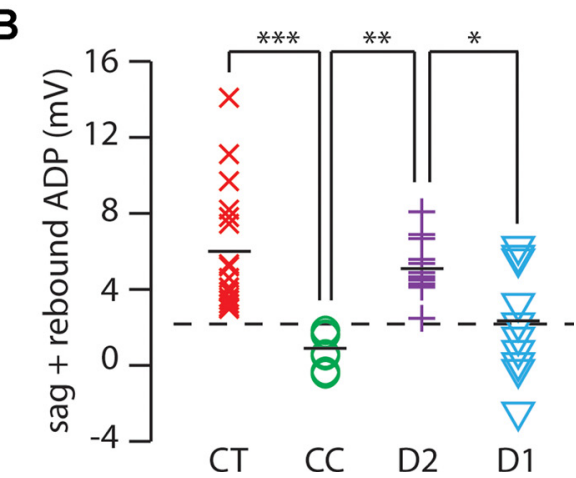

Figure 3. D2Rs are selectively expressed in type A pyramidal neurons which can be distinguished using the h-current. $\boldsymbol{A}$, Low-power confocal images of infralimbic cortex showing the pattern of fluorescence in Drd1-Cre (D1-Cre) and Drd2-Cre (D2-Cre) transgenic mice injected with virus to drive Cre-dependent expression of ChR2-YFP. The corpus callosum and midline lie below and above both images, respectively. $\mathrm{ml}$, midline. Scale bar, $0.1 \mathrm{~mm}$ (both images are to the same scale). $\boldsymbol{B}$, The amount of h-current (measured as above) in identified corticothalamic (CT, $n=18)$, corticocortical (CC, $n=8)$, D2Rexpressing (D2, $n=14)$, or D1R-expressing (D1, $n=10$ ) pyramidal neurons in layer $V$ of $\mathrm{mPFC}$. The dotted line indicates the threshold that separates the distributions of $h$-current from CT and CC neurons. ${ }^{*} p<0.05,{ }^{* *} p<0.01$.

$\mathrm{V}_{\text {rest }}=-60.8 \pm 1.5 \mathrm{mV}, p=0.32, n=8 ; 20 \mu \mathrm{M}$ : control $\mathrm{V}_{\text {rest }}=-62.3 \pm 1.8 \mathrm{mV}$, quinpirole $\mathrm{V}_{\text {rest }}=-60.9 \pm 1.5 \mathrm{mV}$, $p=0.42, n=5)$. For these experiments, we expressed ChR2 in pyramidal neurons in the contralateral $\mathrm{mPFC}$ using viral injection (Fig. 4A; see Materials and Methods). We then recorded from type A neurons that did not express ChR2 while stimulating ChR2-positive corticocortical fibers with trains of randomly occurring light flashes $(470 \mathrm{~nm} ; 2.5 \mathrm{~ms}$ duration; intensity: $\sim 2 \mathrm{~mW}$; rate: $5-50 \mathrm{~Hz}$; train duration: $2.5 \mathrm{~s} ; 5$ trains were delivered with an intertrain interval of $13 \mathrm{~s}$ ). As illustrated in Figure 4 , this led to relatively weak synaptic input that usually evoked zero or only a few spikes in the postsynaptic neuron.

We quantified the quinpirole-induced afterdepolarization by measuring the time for the membrane potential to decay back to 
A

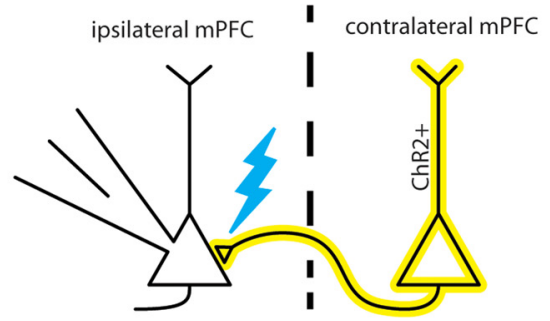

B Control ACSF

before synaptic stim

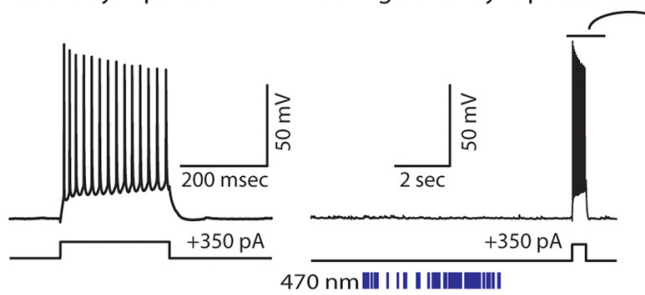

C ( \pm Quinpirole $(20 \mu \mathrm{M}, 22 \mathrm{~min})$
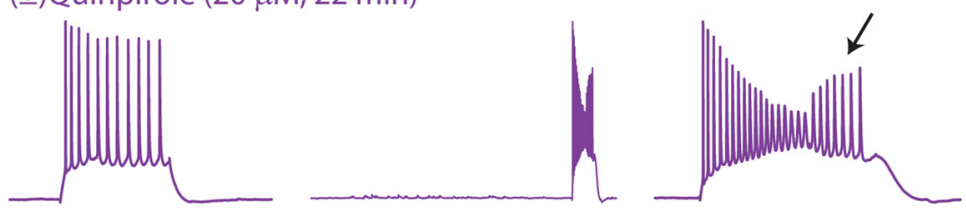

D Quinpirole + APV $(50 \mu \mathrm{M})$
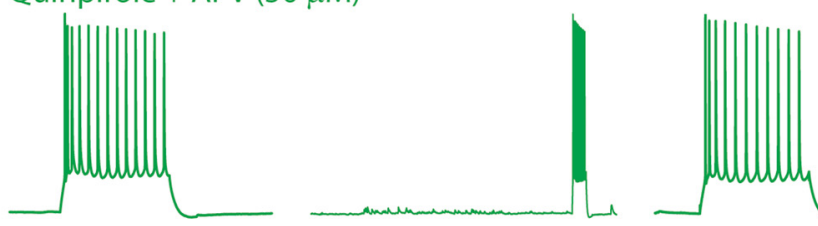

E

Responses after synaptic stimulation: Control

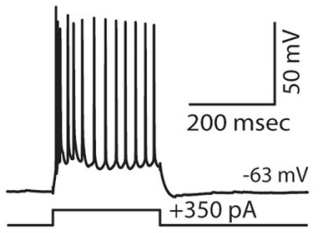

(-)Quinpirole (5 $\mu \mathrm{M}, 20 \mathrm{~min})$

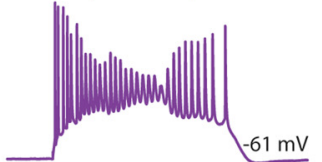

Quinpirole + Nimodipine (1 $\mu \mathrm{M})$

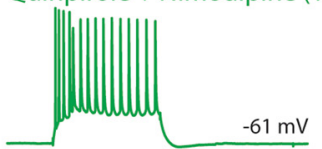

\section{$F$}
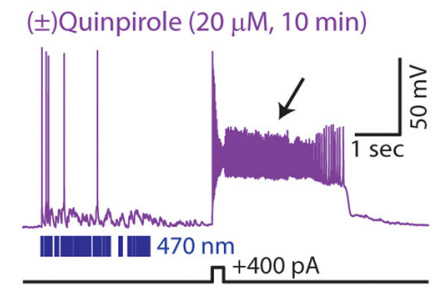

G

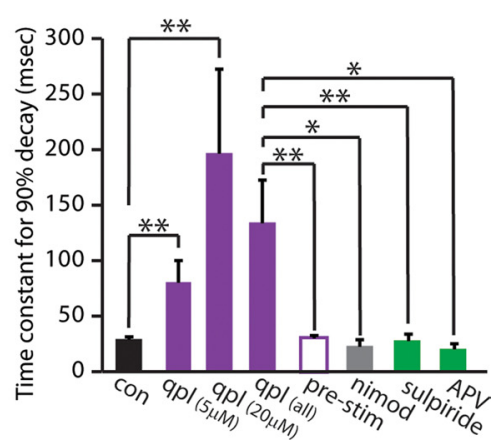

Figure 4. Synaptic stimulation unmasks a novel D2R-mediated afterdepolarization in specific layer V pyramidal neurons. $\boldsymbol{A}$, Experimental design. We recorded from ChR2-negative layer $V$ neurons while stimulating ChR2-positive axons from the contralateral mPFC with trains of light flashes $(470 \mathrm{~nm}, 2.5 \mathrm{~ms}, \sim 2 \mathrm{~mW}$ ). $\boldsymbol{B}$, Responses of a type A layer V pyramidal neuron to current injection before (left) and immediately following (middle and right) optogenetic stimulation of synaptic inputs. Blue bars indicate the times of light flashes. $C$, Before synaptic stimulation, no quinpirole-induced afterdepolarization is observed; however, the same current injection elicits a marked afterdepolarization (along with spike height rundown) following weak synaptic stimulation. $\boldsymbol{D}$, The quinpirole-induced afterdepolarization is eliminated by the addition of AP5. $\boldsymbol{E}$, Lower doses of quinpirole (5 $\mu \mathrm{m})$ also induce an afterdepolarization following synaptic stimulation, which can be blocked by nimodipine ( $1 \mu \mathrm{M})$. $\boldsymbol{F}$, Recording from a type A neuron showing a prolonged quinpirole-induced afterdepolarization following synaptic stimulation. $\mathbf{G}$, Average time constants for the

within $90 \%$ of the baseline membrane potential following a depolarizing current pulse (Fig. 4G). To confirm that D2Rs mediate the quinpirole-induced afterdepolarization, we used the selective D2R antagonist (-)sulpiride. Many studies have used sulpiride at doses up to $10 \mu \mathrm{M}$ to confirm that various phenomena are mediated by D2Rs (Kreitzer and Malenka, 2005; Ramanathan et al., 2008; Ding et al., 2010). Indeed, we found that $5 \mu \mathrm{M}$ $(-)$ sulpiride eliminated the quinpiroleinduced afterdepolarization in $4 / 4$ cells (Fig. $4 G$ ). This dose is $\sim 10$-fold less than the $K_{\mathrm{i}}$ for $(-)$ sulpiride binding to D1Rs in expression systems (Seeman and Van Tol, 1994), and should thus be highly selective for D2Rs in brain slices. The quinpiroleinduced depolarization could be reversed in other ways as well: by addition of the NMDA-R antagonist AP5 (50 $\mu \mathrm{M} ; n=3 / 3$ cells; Fig. $4 C, G$ ) and by addition of the selective L-type $\mathrm{Ca}^{2+}$ channel antagonist nimodipine $(1 \mu \mathrm{M} ; n=3 / 3$ cells; Fig. $4 C, G)$. Furthermore, as shown in Figure $4 G$, the duration of the quinpirole-induced afterdepolarization was larger for $20 \mu \mathrm{M}$ ( \pm )quinpirole $(n=6)$ than for $5 \mu \mathrm{M}$ ( - quinpirole $(n=7)$, although this difference did not reach statistical significance.

Many studies have activated D2Rs using $10 \mu \mathrm{m}$ quinpirole (Wang and GoldmanRakic, 2004; Kreitzer and Malenka, 2005; Ramanathan et al., 2008; Sidiropoulou et al., 2009), similar to the doses we have used (5 or $20 \mu \mathrm{M})$. Nevertheless, these doses are higher than those used in other studies of PFC, e.g., 1-2 $\mu \mathrm{M}$ (Tseng and O'Donnell, 2007; Tseng et al., 2008). We will address possible reasons for these discrepancies (see Discussion), although we remain confident that D2Rs are required for the quinpirole-induced afterdepolarization, because this phenomenon (1) can be elicited by moderate doses of quinpirole $(5 \mu \mathrm{M}),(2)$ occurs selectively in D2Rexpressing neurons, and (3) is blocked by the specific D2R antagonist sulpiride (5 $\mu \mathrm{M})$. Of course, we cannot rule out the possibility that in addition to D2Rs, other receptors also play a role. Since we obtained the most prominent afterdepolar-

membrane potential to return to baseline following a depolarizing current pulse ( $300-400$ pA, $250-500 \mathrm{~ms})$ delivered immediately following the pattern of synaptic stimulation shown above. Data are shown for control conditions (black; $n=12$ ), quinpirole (purple; $5 \mu \mathrm{m}, n=7$; $20 \mu \mathrm{m}, n=6$ ), quinpirole in the absence of synaptic stimulation (hollow purple bar; $5 \mu \mathrm{m}, n=6$ ), nimodipine (gray; $1 \mu \mathrm{m}, n=3$ ), sulpiride (green; $5 \mu \mathrm{m}, n=4$ ), or AP5 (green; $50 \mu \mathrm{m}, n=3$ ). ${ }^{*} p<0.05,{ }^{* *} p<0.01$. 
ization using $20 \mu \mathrm{M}$ ( \pm )quinpirole, we used this dose for subsequent experiments. As described below, all of the effects we observed using $20 \mu \mathrm{M}$ (士)quinpirole were reversed by (-)sulpiride $(5 \mu \mathrm{M})$, confirming that they require D2Rs.

\section{Activating NMDA receptors also unmasks the} quinpirole-induced afterdepolarization

Given that AP5 blocks the ability of synaptic stimulation to unmask the quinpirole-induced afterdepolarization, we tested whether modest levels of NMDA receptor activation might suffice to unmask this effect. Indeed, we observed the quinpiroleinduced afterdepolarization when we included a low concentration of NMDA $(4 \mu \mathrm{M})$ in the bath (Fig. $5 A, B ; n=4)$. Notably, the afterdepolarization was not induced by this concentration of NMDA alone, and was reversed by $(-)$ sulpiride ( $5 \mu \mathrm{M}$; Fig. $5 A, B$; $n=4)$. Figure $5 B$ quantifies and summarizes these effects. The concentration of NMDA we used is within the range used by previous studies to elicit network activity in prefrontal brain slices (3-8 $\mu \mathrm{M})$ (Tseng and O'Donnell, 2005; Stewart and Plenz, 2006).

\section{The quinpirole-induced afterdepolarization is absent from type $B$ neurons}

We also applied $( \pm)$ quinpirole $(20 \mu \mathrm{M})$ to type B neurons $(n=$ 7 ), and measured their responses to depolarizing current pulses (350 pA, $250 \mathrm{~ms}$ ). As in the experiments with type A neurons, depolarizing current pulses either occurred immediately following optogenetic stimulation of excitatory synapses in layer $\mathrm{V}(n=$ $3)$, or with $4 \mu \mathrm{M} \mathrm{NMDA}$ in the bath $(n=4)$. None of these experiments elicited a quinpirole-induced afterdepolarization in type $\mathrm{B}$ neurons. This is quantified in Figure $5 B$, which shows how various conditions affect the time for the membrane potential to return to baseline following a depolarizing current pulse in type $\mathrm{B}$ neurons.

\section{The quinpirole-induced afterdepolarization occurs in perforated-patch recordings}

To rule out the possibility that the afterdepolarization only occurs after dialyzing neurons with our intracellular solution, we verified that we could observe this effect during gramicidin perforated-patch recordings (see Materials and Methods). Indeed, during perforated-patch recordings from type A neurons, coapplication of $( \pm)$ quinpirole $(20 \mu \mathrm{M})$ and NMDA (6 $\mu \mathrm{M})$ elicited an afterdepolarization that was reversed by adding the D2R antagonist $(-)$ sulpiride $(5 \mu \mathrm{M})$ (Fig. $6 A, C ; n=$ $5)$. Two additional details of this experiment were notable. First, in this experiment, we identified type A neurons by injecting Retrobeads into MD thalamus to label CT neurons, and 5/5 labeled CT neurons exhibited the quinpirole-induced afterdepolarization, providing additional evidence that CT neurons express D2Rs. Second, although we monitored the bridge balance for sudden changes indicative of a shift from a perforated-patch to whole-cell recording (compare with $\mathrm{p} 3 \mathrm{vs}$ Fig. $6 \mathrm{~A}$. bottom), in some cases we also included fluorescent dye in the pipette $(0.05 \%$ Lucifer yellow; $n=2)$. As shown in Figure $6 B$, this fluorescent dye was excluded from the neuron while in the perforated-patch configuration (top), but entered the neuron after breaking in and shifting to a whole-cell configuration (bottom).

\section{Quinpirole prolongs $\mathrm{Ca}^{2+}$-mediated plateau potentials}

We next sought to characterize the ion channels that contribute to the quinpirole-induced afterdepolarization. Similar afterde-
A
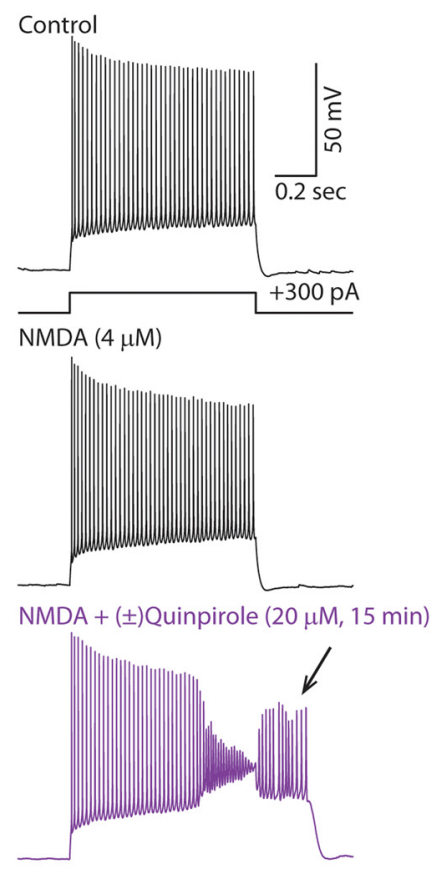

$\mathrm{NMDA}+\mathrm{QPL}+$ Sulpiride $(5 \mu \mathrm{M})$

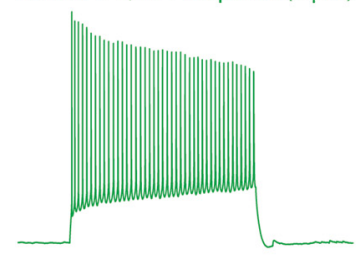

$\mathrm{NMDA}+\mathrm{QPL}+\mathrm{SUL}+\mathrm{AP} 5(50 \mu \mathrm{M})$

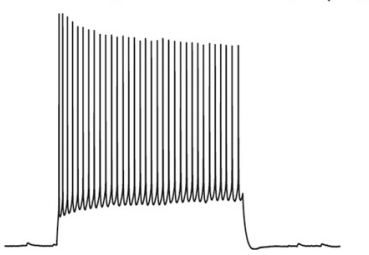

B

Time constant for $90 \%$ decay (msec)
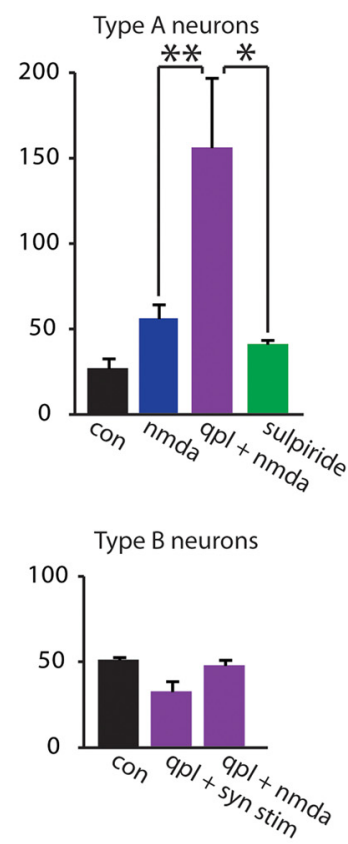

Figure 5. NMDA can unmask the quinpirole-induced afterdepolarization in type A neurons. $A$, Responses of a type A neuron to depolarizing current pulses in various pharmacologic conditions showing that bath application of quinpirole and NMDA, but not NMDA alone, induces an afterdepolarization (arrow) that is reversed by sulpiride. $\boldsymbol{B}$, Top, Summary data showing the effect of quinpirole, NMDA, and sulpiride on the time constant for the membrane potential to return to baseline following depolarizing current pulses (350 pA, $250 \mathrm{~ms}$ ) in type A neurons ( $n=4$ for each condition): control (black), NMDA (blue; $4 \mu \mathrm{M}$ ), ( \pm )quinpirole (purple; 20 $\mu \mathrm{m})+\mathrm{NMDA}$ ), or sulpiride (green; $5 \mu \mathrm{m})+$ quinpirole $+\mathrm{NMDA})$. $\boldsymbol{B}$, Bottom, Quinpirole does not elicit a similar afterdepolarization in type $B$ neurons. The time constant for the membrane potential to return to baseline following depolarization current pulses ( $350 \mathrm{pA}, 250 \mathrm{~ms}$ ) in type B neurons is shown for various conditions: control (black; $n=3)$, ( \pm )quinpirole (20 $\mu \mathrm{m}$ ) following optogenetic synaptic stimulation (purple; $n=3)$, ( \pm )quinpirole $(20 \mu \mathrm{m})$ plus NMDA (4 $\mu \mathrm{m})$ (purple; $n=4) .{ }^{*} p<0.05,{ }^{* *} p<0.01$.

polarizations have been observed in response to 5-HT in turtle motoneurons (Hounsgaard and Kiehn, 1989), in response to D1R stimulation and/or synaptic stimulation in striatal projection neurons (Hernández-López et al., 1997; Vergara et al., 2003), in frog olfactory bulb neurons (Hall and Delaney, 2002), and in nigral GABAergic neurons (Lee and Tepper, 2007). Notably, these other afterdepolarizations also caused spike height rundown very similar to what we observed with quinpirole (e.g., Figs. 4-6). Each of these other afterdepolarizations were generated by combinations of $\mathrm{Ca}^{2+}$ influx via L-type $\mathrm{Ca}^{2+}$ channels and/or 
A

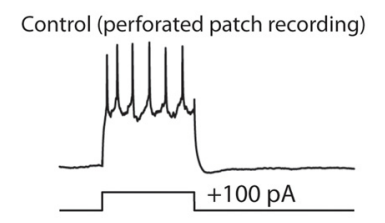

$( \pm)$ Quinpirole $(20 \mu \mathrm{M}, 18 \mathrm{~min})+\mathrm{NMDA}(6 \mu \mathrm{M})$
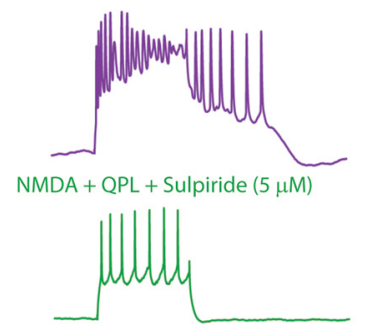

$\mathrm{NMDA}+\mathrm{QPL}+$ Sulpiride

(after breaking in)

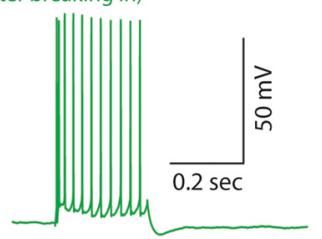

B

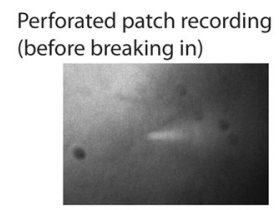

Whole cell recording (after breaking in)

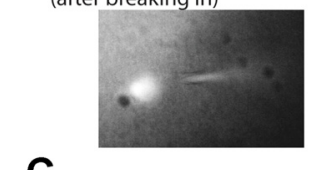

C time constant for $90 \%$ decay (ms) in perforated patch recordings

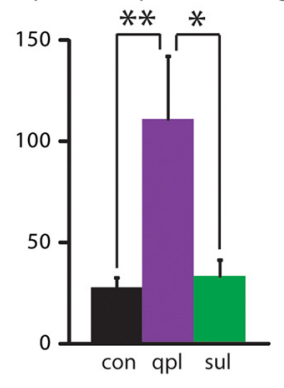

Figure 6. Quinpirole also induces an afterdepolarization during perforated-patch recordings from type A neurons. A, Recordings from a type A neuron in perforated-patch configuration (top three recordings) showing the quinpirole-induced afterdepolarization that occurs in the presence of NMDA, and is reversed by sulpiride. Bottom, shows a recording from the same neuron after breaking in and shifting to a whole-cell recording. $\boldsymbol{B}$, Fluorescent dye in the recording pipette was excluded from the neuron while in the perforated-patch configuration (top), but entered the neuron after breaking in and shifting to a whole-cell configuration (bottom). $C$, Summary data showing that ( \pm )quinpirole $(20 \mu \mathrm{m})$ plus NMDA $(6 \mu \mathrm{m})$ prolongs the time constant for the membrane potential to return to baseline following depolarizing current pulses ( $350 \mathrm{pA}, 250 \mathrm{~ms})$, and that this is reversed by the addition of sulpiride $(5 \mu \mathrm{m})(n=5) .{ }^{*} p<$ $0.05,{ }^{* *} p<0.01$.

NMDA receptors (NMDA-Rs), and the $\mathrm{Ca}^{2+}$-activated nonselective cationic conductance $\left(I_{\mathrm{CAN}}\right)$. Our experiments suggest that a similar mechanism mediates the quinpirole-induced afterdepolarization, since it can be eliminated by antagonizing either L-type $\mathrm{Ca}^{2+}$ channels or NMDA-Rs.

An ideal experiment would be to measure how quinpirole affects L-type $\mathrm{Ca}^{2+}$ currents. However, none of these previous studies of similar afterdepolarizations measured L-type $\mathrm{Ca}^{2+}$ currents directly (Hounsgaard and Kiehn, 1989; HernándezLópez et al., 1997; Hall and Delaney, 2002; Vergara et al., 2003; Lee and Tepper, 2007), because poor space clamp makes it notoriously difficult to isolate and measure regenerative voltagedependent currents in intact pyramidal neurons. In fact, attempting to do so can lead to spurious results (Maurice et al., 2001). Indeed, we attempted to directly measure the effects of quinpirole on voltage-dependent $\mathrm{Ca}^{2+}$ currents, but these recordings suffered from poor space clamp. Similarly, it is extremely challenging to directly measure $\mathrm{Ca}^{2+}$-dependent currents such as $I_{\mathrm{CAN}}$, because the intracellular $\mathrm{Ca}^{2+}$ concentration varies during current-clamp or voltage-clamp recordings. Because of these issues, numerous studies indirectly measured these $\mathrm{Ca}^{2+}$ and $\mathrm{Ca}^{2+}$-dependent currents by studying plateau potentials which occur after blocking voltage-dependent $\mathrm{Na}^{+}$and/or $\mathrm{K}^{+}$currents (Forscher and Oxford, 1985; Hounsgaard and Kiehn, 1989; Hernández-López et al., 1997; Young and Yang, 2004; Lee and Tepper, 2007).

A $\operatorname{TTX}(0.5 \mu \mathrm{M})+\operatorname{TEA}(30 \mathrm{mM})+\operatorname{NMDA}(4 \mu \mathrm{M})$
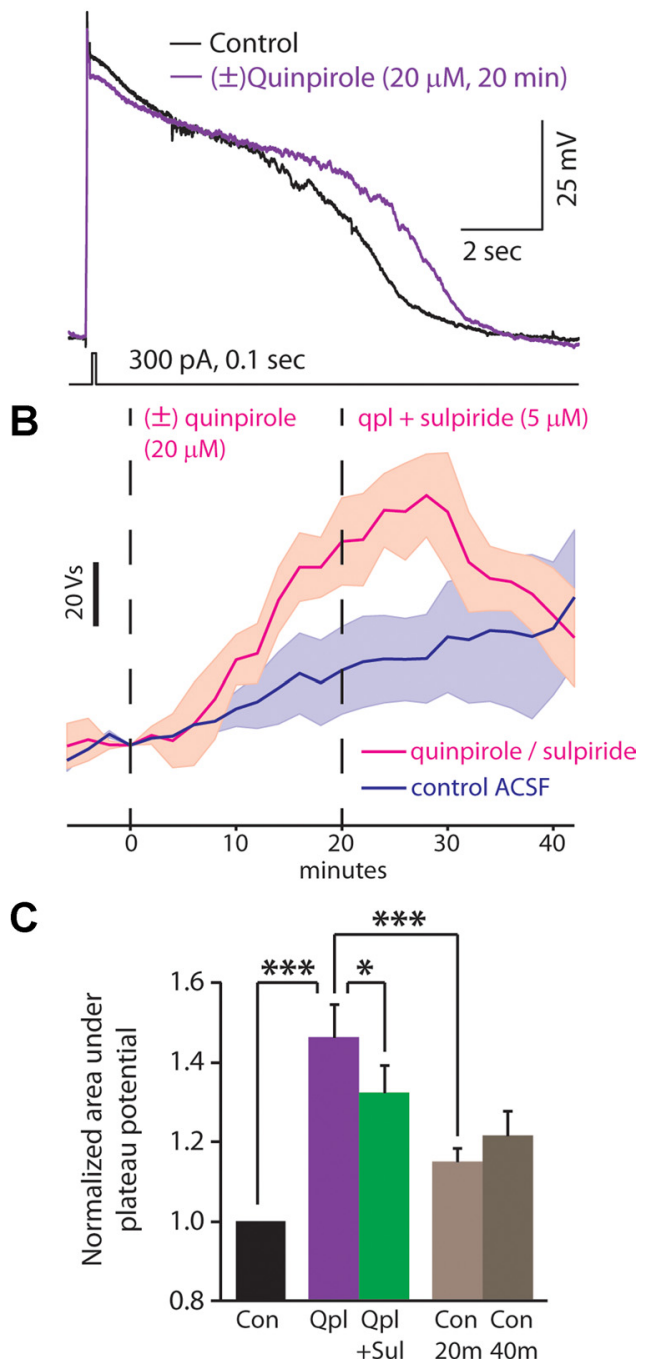

Figure 7. Quinpirole reversibly prolongs calcium-dependent plateau potentials. A, A short current pulse elicits a brief $\mathrm{Ca}^{2+}$ spike that is followed by a prolonged plateau potential in a type $A$ neurons after application of TTX and TEA. Each experiment recorded plateau potentials in control conditions, then while applying ( \pm )quinpirole $(20 \mu \mathrm{M})$, and finally while applying quinpirole + sulpiride $(5 \mu \mathrm{M})$. $\boldsymbol{B}$, We quantified the size of plateau potentials by measuring the area under the voltage trace. The average size of the plateau potentials are shown as a function of time ( $n=4$ cells in each condition). For the magenta trace, $t=0$ represents the beginning of quinpirole application, and quinpirole and sulpiride were both applied after $t=20 \mathrm{~min}$. The dark blue trace represents recordings in control ACSF. Shaded regions represent \pm 1 SEM. C, Summary data for the size of plateau potentials in each condition. Each bar represents data collected from $5 \mathrm{~min}$ before until 5 min after the end of drug application, or corresponding time points during recordings in control ACSF. We measured plateau potentials every 5 min during this period and used repeated-measures ANOVA and corrections for multiple-comparisons to assess statistical significance. ${ }^{*} p<0.05,{ }^{* * *} p<0.001$.

We followed this well established approach and confirmed that quinpirole enhances $\mathrm{Ca}^{2+}$ and/or $\mathrm{Ca}^{2+}$-dependent currents that produce the quinpirole-induced afterdepolarization, by recording plateau potentials that occur after application of TTX $(0.5 \mu \mathrm{M})$ and TEA $(30 \mathrm{mM})$ to block $\mathrm{Na}^{+}$and $\mathrm{K}^{+}$currents (Fig. $7 A$; see Materials and Methods). In these experiments, a brief, strong depolarizing current pulse $(300 \mathrm{pA}, 100 \mathrm{~ms})$ triggers a high-threshold $\mathrm{Ca}^{2+}$ spike that is followed by a long plateau potential. These plateau potentials last several seconds. As a result, although they may contribute to the initial $\mathrm{Ca}^{2+}$ spike, T-type 
$\mathrm{Ca}^{2+}$ channels will be inactivated during the plateau potential. Furthermore, a previous study of layer V-VI pyramidal neurons in PFC found that under these conditions, evoked $\mathrm{Ca}^{2+}$ spikes are driven primarily by L-type $\mathrm{Ca}^{2+}$ channels (Young and Yang, 2004). Based on our earlier experiments, we recorded these plateau potentials in the presence of $4 \mu \mathrm{M}$ NMDA. Thus, these plateau potentials are driven primarily by a combination of L-type $\mathrm{Ca}^{2+}$ currents, NMDA-R-mediated currents, and $\mathrm{Ca}^{2+}$ dependent currents such as the $\mathrm{Ca}^{2+}$-activated nonselective cationic current, $I_{\mathrm{CAN}}$. Other slowly or noninactivating highthreshold $\mathrm{Ca}^{2+}$ currents, e.g., N-type, may also contribute, but likely play a much smaller role (Young and Yang, 2004). We observed a clear increase in these plateau potentials after applying ( \pm )quinpirole $(20 \mu \mathrm{M})$ for $20 \mathrm{~min}$ (Fig. $7 \mathrm{~B}, C)$. This effect was partially reversed by adding $(-)$ sulpiride $(5 \mu \mathrm{M})$ for $20 \mathrm{~min}$ (Fig. $7 B, C ; n=4$ cells; $p<0.001$ control vs quinpirole, $p<0.05$ quinpirole vs quinpirole + sulpiride by repeated-measures ANOVA using cell and condition as factors and after correcting for multiple-comparisons). There was usually a slight increase in the plateau potential over time, so we also measured the size of the plateau potential in control ACSF after $20 \mathrm{~min}$ (corresponding to the time of quinpirole application) and $40 \mathrm{~min}$ (corresponding to the time of sulpiride application). The increase in the size of the plateau potential was much larger in cells for which we applied quinpirole $(n=4)$, compared with cells maintained in control ACSF $(n=4)(p<0.001$ by ANOVA using cell and condition as factors and after correcting for multiple-comparisons). Thus, although it was not possible to directly measure L-type $\mathrm{Ca}^{2+}$ currents or $\mathrm{Ca}^{2+}$-dependent currents, we did confirm that quinpirole enhances $\mathrm{Ca}^{2+}$ and/or $\mathrm{Ca}^{2+}$-dependent currents that produce plateau potentials when $\mathrm{Na}^{+}$and $\mathrm{K}^{+}$ channels are blocked. This, together with our experiments using nimodipine, NMDA, and AP5, strongly suggest that like other similar afterdepolarizations, the quinpirole-induced depolarization is mediated by a combination of $\mathrm{Ca}^{2+}$ currents mediated by L-type channels and NMDA-Rs, as well as depolarizing $\mathrm{Ca}^{2+}$ dependent currents, e.g., $I_{\mathrm{CAN}}$.

\section{Intracellular BAPTA eliminates the quinpirole-induced afterdepolarization}

The experiments described above leave open whether the quinpirole-induced afterdepolarization results simply from $\mathrm{Ca}^{2+}$ currents themselves, or whether the activation of $\mathrm{Ca}^{2+}$ dependent currents, e.g., $I_{\mathrm{CAN}}$, is also required. To provide additional evidence that $\mathrm{Ca}^{2+}$ influx is specifically required for the quinpirole-induced afterdepolarization, we tested whether the afterdepolarization is blocked by the $\mathrm{Ca}^{2+}$ chelator BAPTA, which blocks or attenuates downstream effects of $\mathrm{Ca}^{2+}$ but not $\mathrm{Ca}^{2+}$ currents themselves. We made perforated patch recordings and included BAPTA ( $5 \mathrm{~mm})$ in the intracellular solution. As in previous experiments, we made perforated patch recordings from type A neurons, and observed an afterdepolarization after applying quinpirole and NMDA (Fig. 8A). However, immediately after breaking in and switching to a whole-cell recording configuration, the afterdepolarization and other effects of quinpirole (e.g., decreasing spike heights) disappeared (Fig. 8A, $B$; $n=3 / 3$ cells). In five other neurons, we broke in and switched to a whole-cell configuration (with BAPTA in the pipette) while applying quinpirole. In all of these cases, BAPTA prevented quinpirole from inducing an afterdepolarization (Fig. $8 \mathrm{~B}$ ). Note that the intracellular solution we used in previous experiments contained another $\mathrm{Ca}^{2+}$ chelator-EGTA. However, it is known that BAPTA but not EGTA prevents $\mathrm{Ca}^{2+}$ from activating $I_{\mathrm{CAN}}$

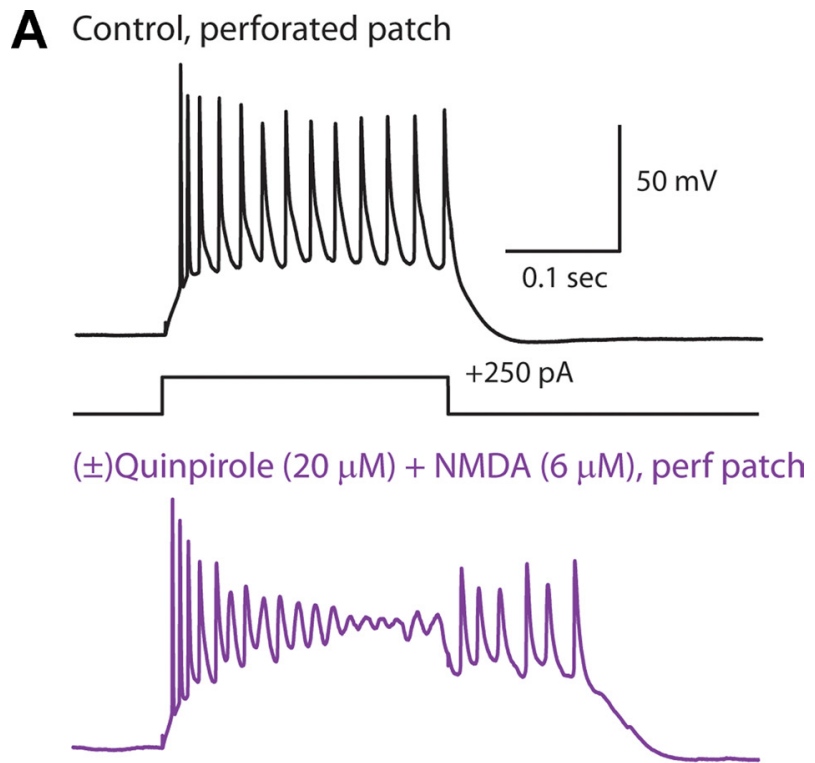

\section{Quinpirole + NMDA, after breaking in with} BAPTA ( $5 \mathrm{mM}$ ) in the intracellular solution

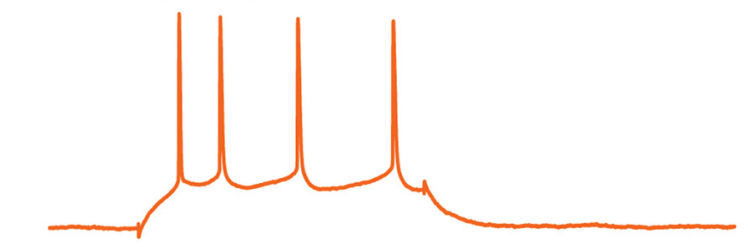

B

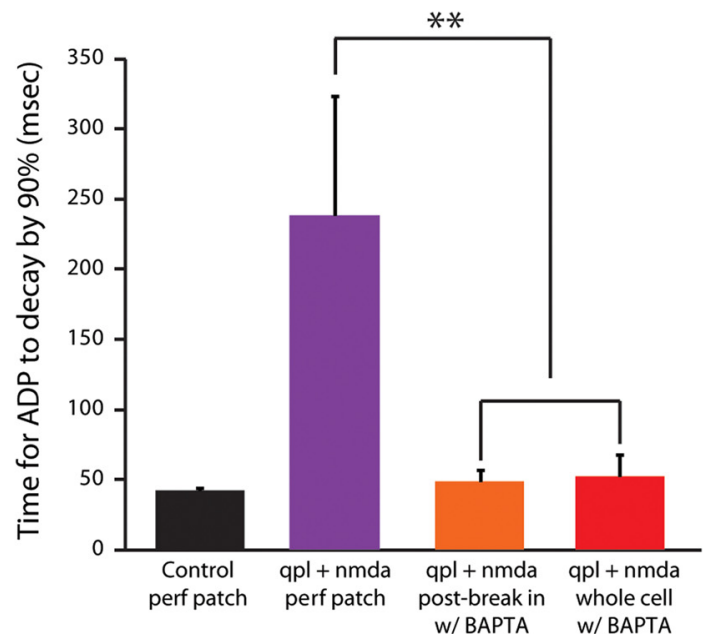

Figure 8. The $\mathrm{Ca}^{2+}$ chelator BAPTA eliminates the quinpirole-induced afterdepolarization. $A$, Perforated patch recording from a type A pyramidal neuron in control conditions (top) and after application of quinpirole + NMDA elicits an afterdepolarization (middle). Bottom, In the same neuron, after breaking in and switching to a whole-cell recording configuration, the quinpirole-induced afterdepolarization is abolished. BAPTA (5 mM) is present in the pipette solution. $\boldsymbol{B}$, Summary data showing time constants for the membrane potential to return to baseline following depolarizing current pulses ( $50-150 \mathrm{pA}$, $250 \mathrm{~ms}$ ) under various conditions. "Control," perforated patch recordings in control ACSF (black; $n=3$ ); "qpl + NMDA, perf patch," the same perforated patch recordings after applying quinpirole and NMDA (orange; $n=3$ ); "qpl + NMDA, postbreak in w/BAPTA," whole-cell recordings from the same cells that were initially recorded in perforated patch configuration (in quinpirole and NMDA) (purple; $n=3$ ); "qpl + NMDA, whole-cell w/BAPTA," recordings from cells that broke in and switched to whole-cell configuration during the application of quinpirole + NMDA (red; $n=5) .{ }^{* *} p<0.01$. 
(Forscher and Oxford, 1985; Hall and Delaney, 2002). In particular, the fact that BAPTA, but not EGTA, blocks the quinpiroleinduced afterdepolarization suggests that this phenomenon depends on $I_{\text {CAN }}$ (which is blocked by BAPTA but not EGTA) but not intracellular $\mathrm{Ca}^{2+}$ acting as a second messenger (which would be blocked equally well by EGTA and BAPTA) (Forscher and Oxford, 1985).

\section{Blocking SK channels can also unmask a quinpirole-induced afterdepolarization}

A previous study of thick-tufted layer $\mathrm{V}$ pyramidal neurons in the mPFC (Wang and Goldman-Rakic, 2004) found that D2R activation reduces the threshold for bursts evoked by synaptic stimulation in the presence of bicuculline and AP5. This study focused on synaptically evoked bursts lasting $\sim 50 \mathrm{~ms}$ instead of afterdepolarizations lasting for hundreds of milliseconds or seconds, and the results of that study were obtained under conditions of $\mathrm{GABA}_{\mathrm{A}}$ and NMDA receptor blockade. Moreover, that study left open whether D2R-mediated increases in synaptically evoked bursting result from presynaptic or postsynaptic effects. Nevertheless, that study, like ours, suggests that D2Rs can enhance the excitability of thick-tufted layer V pyramidal neurons in the mPFC. Thus, the increased bursting observed in that study may result from the same mechanisms which we have found produce the quinpirole-induced afterdepolarization. If this is true, application of bicuculline and AP5 may suffice to unmask the quinpirole-induced afterdepolarization, even in the absence of synaptic stimulation. Indeed, after applying $( \pm)$ quinpirole $(20 \mu \mathrm{M})$, bicuculline $(10 \mu \mathrm{M})$, and AP5 $(50 \mu \mathrm{M})$, we observed an afterdepolarization in type A neurons very similar to the quinpirole-induced afterdepolarization seen in previous experiments (Fig. $9 A, C ; n=3 / 3$ neurons). Moreover, this afterdepolarization was blocked by nimodipine ( $1 \mathrm{~mm} ; n=3$ cells). Thus, even when NMDA-Rs are blocked, quinpirole can still elicit an afterdepolarization, and this afterdepolarization depends on L-type $\mathrm{Ca}^{2+}$ channels. This suggests that $\mathrm{L}$-type $\mathrm{Ca}^{2+}$ channels play a major role in quinpirole-induced afterdepolarizations, whereas NMDA-Rs may facilitate this afterdepolarization, but are not required under all conditions.

In addition to blocking $\mathrm{GABA}_{\mathrm{A}}$ receptors, bicuculline also blocks SK-type $\mathrm{Ca}^{2+}$-dependent $\mathrm{K}^{+}$channels (Johnson and Seutin, 1997; Debarbieux et al., 1998). Therefore, we tested whether the afterdepolarization observed in type A neurons after applying quinpirole, bicuculline, and AP5, depends on the blockade of $\mathrm{GABA}_{\mathrm{A}}$ receptors and/or $\mathrm{SK}$ channels. We found that coapplication of quinpirole and the $\mathrm{GABA}_{\mathrm{A}}$ antagonist gabazine $(10 \mu \mathrm{M})$ did not elicit an afterdepolarization (Fig. $9 C ; n=3$ cells), whereas coapplication of quinpirole and the selective SK channel antagonist apamin $(10 \mu \mathrm{M})$ did elicit an afterdepolarization in type A neurons (Fig. $9 B, C ; n=3$ cells). These results suggest that (1) the mechanism of the quinpirole-induced afterdepolarization may be relevant to the effects of D2Rs on synaptically evoked bursting observed in a previous study, (2) SK channel blockade can unmask quinpirole-induced afterdepolarizations in the absence of synaptic stimulation, and (3) like the quinpirole-induced afterdepolarization which occurs in the presence of synaptic stimulation, the mechanism through which quinpirole increases type A neuron excitability when bicuculline is present also depends on L-type $\mathrm{Ca}^{2+}$ channels.

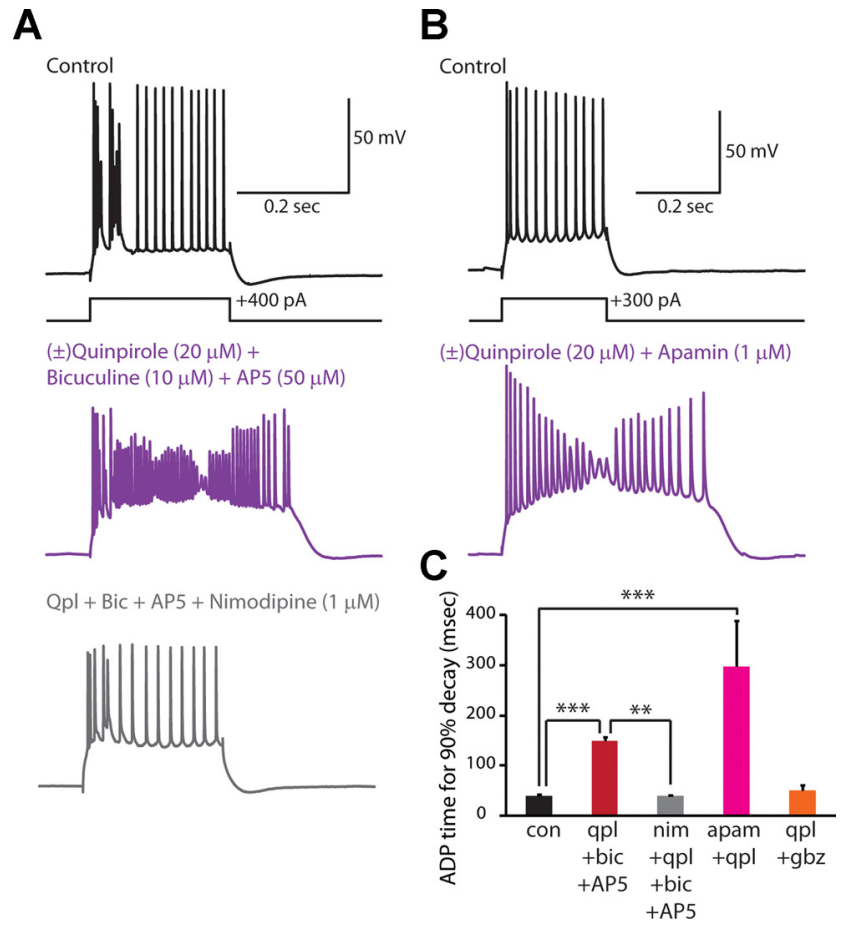

Figure 9. Blocking SK channels and applying quinpirole produces an afterdepolarization that requires $\mathrm{L}$-type $\mathrm{Ca}^{2+}$ channels. $\boldsymbol{A}$, Responses of a type $\mathrm{A}$ neuron to depolarizing current pulses in various pharmacologic conditions showing that bath application of quinpirole, bicuculline, and AP5 induces an afterdepolarization (middle) that is reversed by nimodipine (bottom). $\boldsymbol{B}$, Responses of another type A neuron showing that application of quinpirole and apamin induces a similar afterdepolarization (middle). C, Summary data showing the effect of various conditions on the time constant for the membrane potential to return to baseline following depolarizing current pulses ( $350 \mathrm{pA}, 250 \mathrm{~ms}$ ) in type $\mathrm{A}$ neurons: control (black; $n=10)$, quinpirole + bicuculline + AP5 (red; $n=3)$, quinpirole + bicuculline + AP5 + nimodipine (gray; $n=3$ ), apamin + quinpirole (magenta; $n=3$ ), quinpirole + gabazine (orange; $10 \mu \mathrm{m}, n=4$ ). ${ }^{* *} p<0.01$, ${ }^{* *} p<$ 0.001 .

\section{Discussion}

We have characterized a novel afterdepolarization elicited by D2Rs in the mPFC. This afterdepolarization depends on L-type $\mathrm{Ca}^{2+}$ channels and NMDA-Rs. The afterdepolarization and D2R expression both occur within a specific subpopulation of layer $\mathrm{V}$ pyramidal neurons that have a characteristic morphology (thick-tufted), projection targets (thalamus), and electrophysiological signature (prominent h-current). This suggests that as in striatum, prefrontal D2Rs are restricted to specific cell populations.

As described below, the quinpirole-induced afterdepolarization may underlie numerous functional and pathological effects of prefrontal D2Rs including enhancing firing during memory-guided saccades (Wang et al., 2004), generating persistent reward-related firing (Histed et al., 2009; Bernacchia et al., 2011), or increasing the variability of activity (Winterer and Weinberger, 2004; Durstewitz and Seamans, 2008). In addition, this afterdepolarization may alter prefrontal output to structures including the MD thalamus, which is important for processes such as corollary discharge (Sommer and Wurtz, 2006). Notably, the quinpirole-induced afterdepolarization may represent a mechanism for the long-standing observation that dopamine application to frontal cortical neurons in vivo produces a depolarization accompanied by reduced spike heights (Bernardi et al., 1982). Another study also observed 
reduced spike heights following D2R activation in deep layer mPFC neurons (Sesack and Bunney, 1989). From an extracellular perspective, reduced spike heights would look like an inhibition in firing. Thus, the quinpirole-induced afterdepolarization and accompanying decrease in spike heights may also provide one mechanism for the classical finding that dopamine inhibits subcortically projecting $\mathrm{mPFC}$ neurons via D2Rs in vivo (Godbout et al., 1991; Pirot et al., 1992).

\section{The dose dependence of the}

\section{quinpirole-induced afterdepolarization}

Many studies have activated D2Rs using $10 \mu \mathrm{M}$ quinpirole (Wang and Goldman-Rakic, 2004; Kreitzer and Malenka, 2005; Ramanathan et al., 2008; Sidiropoulou et al., 2009), similar to the doses used here (5 or $20 \mu \mathrm{M}$ ). Notably, Sidiropoulou et al. (2009) applied $10 \mu \mathrm{M}$ quinpirole to layer V pyramidal neurons in PFC without activating D1Rs. Thus, we are confident that the quinpirole-induced afterdepolarization requires D2Rs, since it occurs selectively in D2R-expressing neurons, can be elicited by 5 $\mu \mathrm{M}$ quinpirole, and is eliminated by $5 \mu \mathrm{M}(-)$ sulpiride, which selectively antagonizes D2Rs (Seeman and Van Tol, 1994).

So why is this afterdepolarization most prominent using 20 $\mu \mathrm{M}$ quinpirole, whereas quinpirole exerts distinct effects at lower doses (1-2 $\mu \mathrm{M}$ ) (Tseng and O'Donnell, 2004; Tseng et al., 2008)? D2Rs couple to numerous signaling pathways, mediated by $\mathrm{G}_{\beta \gamma}$, $\beta$-arrestins, and scaffolding proteins (Bonci and Hopf, 2005). D2R ligands possess functional selectivity for these pathways (Mailman, 2007), and the dose dependence of quinpirole likely varies across these pathways (Urban et al., 2007). Notably, effects mediated by $\beta$-arrestin have a time course $\sim 10 \mathrm{~min}$ (Ahn et al., 2004 ), similar to what we observed. Thus, although quinpirole may bind D2Rs at concentrations $<1 \mu \mathrm{M}$, concentrations $\sim 1-2$ $\mu \mathrm{M}$ might recruit certain signaling pathways, while concentrations $\sim 5-20 \mu \mathrm{M}$ elicit distinct effects via noncanonical signaling pathways that are mediated by scaffolding proteins or receptor internalization. It will be important for future studies to elucidate these pathways.

\section{Why haven't previous studies observed the quinpirole-induced afterdepolarization?}

The quinpirole-induced afterdepolarization is masked in quiescent slices, and could be unmasked via physiologic levels of synaptic stimulation or NMDA application $(4-6 \mu \mathrm{M})$. One possible explanation is that the afterdepolarization originates in the dendrites, where D2Rs can be located (Negyessy and GoldmanRakic, 2005). Thus, somatic recordings might not reveal D2R effects until dendritic excitability has been sufficiently enhanced by synaptic stimulation or NMDA. Indeed, while dopamine receptor effects have been extensively studied (Seamans and Yang, 2004), stimulating synapses using optogenetics might produce a more physiological state, thereby revealing phenomena as illustrated here.

Other studies have described distinct effects of quinpirole on layer $\mathrm{V}$ pyramidal neurons. Lower doses of quinpirole inhibit increases in pyramidal neuron excitability caused by AMPA or NMDA (Tseng and O'Donnell, 2004). The effects of quinpirole on responses to NMDA were mediated by D2Rs in inhibitory interneurons, rather than direct effects of D2Rs on pyramidal neurons. It is unclear whether this effect occurs under the same conditions or in the same neurons as the quinpirole-induced afterdepolarization, but this could be an important mechanism for regulating activity driven by the quinpirole-induced afterdepolarization. Indeed, inhibition might normally suppress this afterdepolarization, but pathological afterdepolarizations may emerge when prefrontal inhibition is compromised in schizophrenia or other conditions (Lewis et al., 2005).

Another study (Wang and Goldman-Rakic, 2004) found that doses of quinpirole similar to those used here promote bursting by thick-tufted layer $\mathrm{V}$ neurons in response to synaptic input when bicuculline and AP5 are present. We found that coapplying quinpirole, bicuculline, and AP5 also elicits an afterdepolarization that is blocked by nimodipine. Thus, the mechanism of the quinpirole-induced afterdepolarization may also underlie D2Rinduced increases in bursting observed in that study.

\section{The quinpirole-induced afterdepolarization depends on L-type $\mathrm{Ca}^{2+}$ channels and NMDA-Rs}

We have shown that (1) D2R activation enhances plateau potentials mediated by $\mathrm{Ca}^{2+}$ and $\mathrm{Ca}^{2+}$-dependent currents, (2) the quinpirole-induced afterdepolarization involves both L-type channels and NMDA-Rs, and (3) chelating intracellular $\mathrm{Ca}^{2+}$ blocks the afterdepolarization. Thus, although D2Rs must enhance $\mathrm{Ca}^{2+}$ currents and/or $\mathrm{Ca}^{2+}$-dependent currents underlying the quinpirole-induced afterdepolarization, we cannot pinpoint the exact location of D2R action. Specifically, D2Rs might directly or indirectly enhance L-type currents and the accumulation of intracellular $\mathrm{Ca}^{2+}$ and/or $I_{\text {CAN }}$. We found that in the presence of bicuculline, quinpiroleinduced afterdepolarizations occur even after blocking NMDA-Rs. This suggests that NMDA-Rs facilitate, but are not absolutely necessary for these afterdepolarizations. Thus, D2Rs do not elicit the afterdepolarization via direct actions on NMDA-Rs. Of note, D1Rs in layer V pyramidal neurons in PFC can suppress L-type $\mathrm{Ca}^{2+}$ channel-mediated potentials (Young and Yang, 2004). Since D1Rs and D2Rs often have opposing effects on overlapping signaling pathways, this suggests that D2Rs may enhance L-type $\mathrm{Ca}^{2+}$ channel-mediated phenomena, contributing to the afterdepolarization we found.

L-type $\mathrm{Ca}^{2+}$ channels and NMDA-Rs produce other afterdepolarizations similar to those we have observed (Hounsgaard and Kiehn, 1989; Hernández-López et al., 1997; Hall and Delaney, 2002; Vergara et al., 2003; Lee and Tepper, 2007). Specifically, muscarinic receptors elicit similar afterdepolarizations in layer $\mathrm{V}$ of PFC (Haj-Dahmane and Andrade, 1998, 1999). Many of these afterdepolarizations also cause spike height rundown. Synergistic interactions between L-type $\mathrm{Ca}^{2+}$ channels and NMDA-Rs also produce regenerative depolarizations in pyramidal neuron dendrites (Schiller et al., 2000; Branco and Hausser, 2011). D2R activation could further amplify these interactions, by enhancing L-type $\mathrm{Ca}^{2+}$ currents and/or $I_{\mathrm{CAN}}$. In this way, D2Rs could profoundly enhance synaptic integration (Branco and Hausser, 2011).

\section{L-type $\mathrm{Ca}^{2+}$ channels in PFC function and mental illness}

L-type $\mathrm{Ca}^{2+}$ channels have been implicated in schizophrenia (Bigos et al., 2010; Green et al., 2010; Nyegaard et al., 2010; Ripke et al., 2011). A genetic polymorphism that increases L-type $\mathrm{Ca}^{2+}$ channel expression and schizophrenia risk also reduces prefrontal efficiency (Bigos et al., 2010), and L-type $\mathrm{Ca}^{2+}$ channel antagonists have shown promise for schizophrenia (Yamada et al., 1995, 1996; Schwartz et al., 1997). L-type $\mathrm{Ca}^{2+}$ channels are also implicated in autism (Splawski et al., 2004) and bipolar disorder (Ferreira et al., 2008; Sklar et al., 2011). Despite these findings, specific mechanisms by which L-type $\mathrm{Ca}^{2+}$ channels modulate prefrontal function are lacking. Our results demonstrate an after- 
depolarization through which L-type $\mathrm{Ca}^{2+}$ channels powerfully modulate prefrontal neurons. This may have consequences as described below.

\section{The quinpirole-induced afterdepolarization in PFC function and mental illness}

Layer $\mathrm{V}$ neurons exhibiting the quinpirole-induced afterdepolarization are well poised to affect the cognitive domains disrupted in schizophrenia. As we have shown, layer $\mathrm{V}$ pyramidal neurons that express D2Rs and exhibit the quinpirole-induced afterdepolarization correspond to a subpopulation ("type A") that projects subcortically but not to contralateral PFC. In particular, our finding that D2Rs are restricted to type A neurons while D1Rs are expressed in type B neurons (which project cortically) as well, could explain the recent observation that blocking D1Rs in the frontal eyes fields modulates firing in visual cortex and brainstem, whereas activating D2Rs modulates activity in brainstem but not visual cortex (Noudoost and Moore, 2011). D2Rs might specifically enhance spiking in prefrontal neurons that trigger motor responses or corollary discharges (Robbins, 1990; Frith, 1995; Wang et al., 2004) — processes that are believed to depend on D2Rs and be abnormal in schizophrenia.

The quinpirole-induced afterdepolarization may also contribute to persistent reward-related activity or the modulation of firing by the past history of reward (Histed et al., 2009; Bernacchia et al., 2011). Although the timescales of these phenomena may exceed those shown for the quinpirole-induced afterdepolarization, synaptic input interacts powerfully with the afterdepolarization. Thus, in vivo the quinpirole-induced afterdepolarization may amplify responses to weak synaptic input, producing additional firing and $\mathrm{Ca}^{2+}$ influx that sustain this afterdepolarization over longer timescales.

Finally, the quinpirole-induced afterdepolarization might increase the variability of PFC activity, facilitating adaptation to a changing environment (Durstewitz and Seamans, 2008; Durstewitz et al., 2010). Excessive D2R activation could produce noisy firing that is disconnected from external input and contributes to psychosis.

In summary, these findings define a novel mechanism, involving $\mathrm{Ca}^{2+}$ channels, through which D2Rs can powerfully regulate output from a defined subpopulation of prefrontal neurons. This mechanism is well positioned to modulate prefrontal-dependent behaviors, including those disrupted in mental illness.

\section{References}

Ahn S, Shenoy SK, Wei H, Lefkowitz RJ (2004) Differential kinetic and spatial patterns of beta-arrestin and $\mathrm{G}$ protein-mediated ERK activation by the angiotensin II receptor. J Biol Chem 279:35518-35525.

Arnsten AF, Goldman-Rakic PS (1998) Noise stress impairs prefrontal cortical cognitive function in monkeys: evidence for a hyperdopaminergic mechanism. Arch Gen Psychiatry 55:362-368.

Arnsten AF, Cai JX, Steere JC, Goldman-Rakic PS (1995) Dopamine D2 receptor mechanisms contribute to age-related cognitive decline: the effects of quinpirole on memory and motor performance in monkeys. J Neurosci15:3429-3439.

Bernacchia A, Seo H, Lee D, Wang XJ (2011) A reservoir of time constants for memory traces in cortical neurons. Nat Neurosci 14:366-372.

Bernardi G, Cherubini E, Marciani MG, Mercuri N, Stanzione P (1982) Responses of intracellularly recorded cortical neurons to the iontophoretic application of dopamine. Brain Res 245:267-274.

Bigos KL, Mattay VS, Callicott JH, Straub RE, Vakkalanka R, Kolachana B, Hyde TM, Lipska BK, Kleinman JE, Weinberger DR (2010) Genetic variation in CACNA1C affects brain circuitries related to mental illness. Arch Gen Psychiatry 67:939-945.

Bonci A, Hopf FW (2005) The dopamine D2 receptor: new surprises from an old friend. Neuron 47:335-338.
Branco T, Häusser M (2011) Synaptic integration gradients in single cortical pyramidal cell dendrites. Neuron 69:885-892.

Brown SP, Hestrin S (2009) Intracortical circuits of pyramidal neurons reflect their long-range axonal targets. Nature 457:1133-1136.

Brozoski TJ, Brown RM, Rosvold HE, Goldman PS (1979) Cognitive deficit caused by regional depletion of dopamine in prefrontal cortex of rhesus monkey. Science 205:929-932.

Debarbieux F, Brunton J, Charpak S (1998) Effect of bicuculline on thalamic activity: a direct blockade of IAHP in reticularis neurons. J Neurophysiol 79:2911-2918.

Dembrow NC, Chitwood RA, Johnston D (2010) Projection-specific neuromodulation of medial prefrontal cortex neurons. J Neurosci 30:16922-16937.

Ding JB, Guzman JN, Peterson JD, Goldberg JA, Surmeier DJ (2010) Thalamic gating of corticostriatal signaling by cholinergic interneurons. Neuron 67:294-307.

Druzin MY, Kurzina NP, Malinina EP, Kozlov AP (2000) The effects of local application of $\mathrm{D} 2$ selective dopaminergic drugs into the medial prefrontal cortex of rats in a delayed spatial choice task. Behav Brain Res 109:99-111.

Durstewitz D, Seamans JK (2008) The dual-state theory of prefrontal cortex dopamine function with relevance to catechol-o-methyltransferase genotypes and schizophrenia. Biol Psychiatry 64:739-749.

Durstewitz D, Vittoz NM, Floresco SB, Seamans JK (2010) Abrupt transitions between prefrontal neural ensemble states accompany behavioral transitions during rule learning. Neuron 66:438-448.

Egan MF, Goldberg TE, Kolachana BS, Callicott JH, Mazzanti CM, Straub RE, Goldman D, Weinberger DR (2001) Effect of COMT Val108/158 Met genotype on frontal lobe function and risk for schizophrenia. Proc Natl Acad Sci U S A 98:6917-6922.

Ferreira MA, et al. (2008) Collaborative genome-wide association analysis supports a role for ANK3 and CACNA1C in bipolar disorder. Nat Genet 40:1056-1058.

Floresco SB, Magyar O, Ghods-Sharifi S, Vexelman C, Tse MT (2006) Multiple dopamine receptor subtypes in the medial prefrontal cortex of the rat regulate set-shifting. Neuropsychopharmacology 31:297-309.

Forscher P, Oxford GS (1985) Modulation of calcium channels by norepinephrine in internally dialyzed avian sensory neurons. J Gen Physiol 85:743-763.

Frith C (1995) Functional imaging and cognitive abnormalities. Lancet 346:615-620.

Godbout R, Mantz J, Pirot S, Glowinski J, Thierry AM (1991) Inhibitory influence of the mesocortical dopaminergic neurons on their target cells: electrophysiological and pharmacological characterization. J Pharmacol Exp Ther 258:728-738.

Gong S, Zheng C, Doughty ML, Losos K, Didkovsky N, Schambra UB, Nowak NJ, Joyner A, Leblanc G, Hatten ME, Heintz N (2003) A gene expression atlas of the central nervous system based on bacterial artificial chromosomes. Nature 425:917-925.

Green EK, Grozeva D, Jones I, Jones L, Kirov G, Caesar S, Gordon-Smith K, Fraser C, Forty L, Russell E, Hamshere ML, Moskvina V, Nikolov I, Farmer A, McGuffin P, Holmans PA, Owen MJ, O'Donovan MC, Craddock N (2010) The bipolar disorder risk allele at CACNA1C also confers risk of recurrent major depression and of schizophrenia. Mol Psychiatry 15:1016-1022.

Gulledge AT, Jaffe DB (1998) Dopamine decreases the excitability of layer V pyramidal cells in the rat prefrontal cortex. J Neurosci 18:9139-9151.

Haj-Dahmane S, Andrade R (1998) Ionic mechanism of the slow afterdepolarization induced by muscarinic receptor activation in rat prefrontal cortex. J Neurophysiol 80:1197-1210.

Haj-Dahmane S, Andrade R (1999) Muscarinic receptors regulate two different calcium-dependent non-selective cation currents in rat prefrontal cortex. Eur J Neurosci 11:1973-1980.

Hall BJ, Delaney KR (2002) Contribution of a calcium-activated nonspecific conductance to NMDA receptor-mediated synaptic potentials in granule cells of the frog olfactory bulb. J Physiol 543:819-834.

Hattox AM, Nelson SB (2007) Layer V neurons in mouse cortex projecting to different targets have distinct physiological properties. J Neurophysiol 98:3330-3340.

Hernández-López S, Bargas J, Surmeier DJ, Reyes A, Galarraga E (1997) D1 receptor activation enhances evoked discharge in neostriatal medium spiny neurons by modulating an L-type Ca2 + conductance. J Neurosci $17: 3334-3342$ 
Histed MH, Pasupathy A, Miller EK (2009) Learning substrates in the primate prefrontal cortex and striatum: sustained activity related to successful actions. Neuron 63:244-253.

Hounsgaard J, Kiehn O (1989) Serotonin-induced bistability of turtle motoneurones caused by a nifedipine-sensitive calcium plateau potential. J Physiol 414:265-282.

Johnson SW, Seutin V (1997) Bicuculline methiodide potentiates NMDAdependent burst firing in rat dopamine neurons by blocking apaminsensitive Ca2+-activated K+ currents. Neurosci Lett 231:13-16.

Kellendonk C, Simpson EH, Polan HJ, Malleret G, Vronskaya S, Winiger V, Moore H, Kandel ER (2006) Transient and selective overexpression of dopamine $\mathrm{D} 2$ receptors in the striatum causes persistent abnormalities in prefrontal cortex functioning. Neuron 49:603-615.

Kravitz AV, Freeze BS, Parker PR, Kay K, Thwin MT, Deisseroth K, Kreitzer AC (2010) Regulation of parkinsonian motor behaviours by optogenetic control of basal ganglia circuitry. Nature 466:622-626.

Kreitzer AC, Malenka RC (2005) Dopamine modulation of state-dependent endocannabinoid release and long-term depression in the striatum. J Neurosci 25:10537-10545.

Lee CR, Tepper JM (2007) A calcium-activated nonselective cation conductance underlies the plateau potential in rat substantia nigra GABAergic neurons. J Neurosci 27:6531-6541.

Lewis DA, Hashimoto T, Volk DW (2005) Cortical inhibitory neurons and schizophrenia. Nat Rev Neurosci 6:312-324.

Lidow MS, Wang F, Cao Y, Goldman-Rakic PS (1998) Layer V neurons bear the majority of mRNAs encoding the five distinct dopamine receptor subtypes in the primate prefrontal cortex. Synapse 28:10-20.

Lobo MK, Karsten SL, Gray M, Geschwind DH, Yang XW (2006) FACSarray profiling of striatal projection neuron subtypes in juvenile and adult mouse brains. Nat Neurosci 9:443-452.

Mailman RB (2007) GPCR functional selectivity has therapeutic impact. Trends Pharmacol Sci 28:390-396.

Maurice N, Tkatch T, Meisler M, Sprunger LK, Surmeier DJ (2001) D1/D5 dopamine receptor activation differentially modulates rapidly inactivating and persistent sodium currents in prefrontal cortex pyramidal neurons. J Neurosci 21:2268-2277.

Minton GO, Young AH, McQuade R, Fairchild G, Ingram CD, Gartside SE (2009) Profound changes in dopaminergic neurotransmission in the prefrontal cortex in response to flattening of the diurnal glucocorticoid rhythm: implications for bipolar disorder. Neuropsychopharmacology 34:2265-2274.

Minzer K, Lee O, Hong JJ, Singer HS (2004) Increased prefrontal D2 protein in Tourette syndrome: a postmortem analysis of frontal cortex and striatum. J Neurol Sci 219:55-61.

Morishima M, Kawaguchi Y (2006) Recurrent connection patterns of corticostriatal pyramidal cells in frontal cortex. J Neurosci 26:4394-4405.

Negyessy L, Goldman-Rakic PS (2005) Subcellular localization of the dopamine $\mathrm{D} 2$ receptor and coexistence with the calcium-binding protein neuronal calcium sensor-1 in the primate prefrontal cortex. J Comp Neurol 488:464-475.

Noudoost B, Moore T (2011) Control of visual cortical signals by prefrontal dopamine. Nature 474:372-375.

Nyegaard M, Demontis D, Foldager L, Hedemand A, Flint TJ, Sørensen KM, Andersen PS, Nordentoft M, Werge T, Pedersen CB, Hougaard DM, Mortensen PB, Mors O, Børglum AD (2010) CACNA1C (rs1006737) is associated with schizophrenia. Mol Psychiatry 15:119-121.

Otsuka T, Kawaguchi Y (2008) Firing-pattern-dependent specificity of cortical excitatory feed-forward subnetworks. J Neurosci 28:11186-11195.

Pirot S, Godbout R, Mantz J, Tassin JP, Glowinski J, Thierry AM (1992) Inhibitory effects of ventral tegmental area stimulation on the activity of prefrontal cortical neurons: evidence for the involvement of both dopaminergic and GABAergic components. Neuroscience 49:857-865.

Ramanathan S, Tkatch T, Atherton JF, Wilson CJ, Bevan MD (2008) D2like dopamine receptors modulate SKCa channel function in subthalamic nucleus neurons through inhibition of Cav2.2 channels. J Neurophysiol 99:442-459.

Ripke S, et al. (2011) Genome-wide association study identifies five new schizophrenia loci. Nat Genet 43:969-976.

Robbins TW (1990) The case of frontostriatal dysfunction in schizophrenia. Schizophr Bull 16:391-402.

Santana N, Mengod G, Artigas F (2009) Quantitative analysis of the expres- sion of dopamine D1 and D2 receptors in pyramidal and GABAergic neurons of the rat prefrontal cortex. Cereb Cortex 19:849-860.

Schiller J, Major G, Koester HJ, Schiller Y (2000) NMDA spikes in basal dendrites of cortical pyramidal neurons. Nature 404:285-289.

Schultz W (2007) Multiple dopamine functions at different time courses. Annu Rev Neurosci 30:259-288.

Schwartz BL, Fay-McCarthy M, Kendrick K, Rosse RB, Deutsch SI (1997) Effects of nifedipine, a calcium channel antagonist, on cognitive function in schizophrenic patients with tardive dyskinesia. Clin Neuropharmacol 20:364-370.

Seamans JK, Yang CR (2004) The principal features and mechanisms of dopamine modulation in the prefrontal cortex. Prog Neurobiol 74:1-58.

Seeman P, Van Tol HH (1994) Dopamine receptor pharmacology. Trends Pharmacol Sci 15:264-270.

Sesack SR, Bunney BS (1989) Pharmacological characterization of the receptor mediating electrophysiological responses to dopamine in the rat medial prefrontal cortex: a microiontophoretic study. J Pharmacol Exp Ther 248:1323-1333.

Sheets PL, Suter BA, Kiritani T, Chan CS, Surmeier DJ, Shepherd GM (2011) Corticospinal-specific HCN expression in mouse motor cortex: Ihdependent synaptic integration as a candidate microcircuit mechanism involved in motor control. J Neurophysiol 106:2216-2231.

Sidiropoulou K, Lu FM, Fowler MA, Xiao R, Phillips C, Ozkan ED, Zhu MX, White FJ, Cooper DC (2009) Dopamine modulates an mGluR5mediated depolarization underlying prefrontal persistent activity. Nat Neurosci 12:190-199.

Simonic I, Gericke GS, Ott J, Weber JL (1998) Identification of genetic markers associated with Gilles de la Tourette syndrome in an Afrikaner population. Am J Hum Genet 63:839-846.

Sklar P, et al. (2011) Large-scale genome-wide association analysis of bipolar disorder identifies a new susceptibility locus near ODZ4. Nat Genet 43:977-983.

Sohal VS, Huguenard JR (2005) Inhibitory coupling specifically generates emergent gamma oscillations in diverse cell types. Proc Natl Acad Sci U S A 102:18638-18643.

Sohal VS, Zhang F, Yizhar O, Deisseroth K (2009) Parvalbumin neurons and gamma rhythms enhance cortical circuit performance. Nature 459:698-702.

Sommer MA, Wurtz RH (2006) Influence of the thalamus on spatial visual processing in frontal cortex. Nature 444:374-377.

Splawski I, Timothy KW, Sharpe LM, Decher N, Kumar P, Bloise R, Napolitano C, Schwartz PJ, Joseph RM, Condouris K, Tager-Flusberg H, Priori SG, Sanguinetti MC, Keating MT (2004) Ca(V)1.2 calcium channel dysfunction causes a multisystem disorder including arrhythmia and autism. Cell 119:19-31.

Steeves TD, Ko JH, Kideckel DM, Rusjan P, Houle S, Sandor P, Lang AE, Strafella AP (2010) Extrastriatal dopaminergic dysfunction in Tourette syndrome. Ann Neurol 67:170-181.

Stewart CV, Plenz D (2006) Inverted-U profile of dopamine-NMDAmediated spontaneous avalanche recurrence in superficial layers of rat prefrontal cortex. J Neurosci 26:8148-8159.

St Onge JR, Abhari H, Floresco SB (2011) Dissociable contributions by prefrontal D1 and D2 receptors to risk-based decision making. J Neurosci 31:8625-8633.

Tseng KY, O’Donnell P (2004) Dopamine-glutamate interactions controlling prefrontal cortical pyramidal cell excitability involve multiple signaling mechanisms. J Neurosci 24:5131-5139.

Tseng KY, O’Donnell P (2005) Post-pubertal emergence of prefrontal cortical up states induced by D1-NMDA co-activation. Cereb Cortex 15:49-57.

Tseng KY, O'Donnell P (2007) D2 dopamine receptors recruit a GABA component for their attenuation of excitatory synaptic transmission in the adult rat prefrontal cortex. Synapse 61:843-850.

Tseng KY, Lewis BL, Hashimoto T, Sesack SR, Kloc M, Lewis DA, O'Donnell P (2008) A neonatal ventral hippocampal lesion causes functional deficits in adult prefrontal cortical interneurons. J Neurosci 28:12691-12699.

Urban JD, Clarke WP, von Zastrow M, Nichols DE, Kobilka B, Weinstein H, Javitch JA, Roth BL, Christopoulos A, Sexton PM, Miller KJ, Spedding M, Mailman RB (2007) Functional selectivity and classical concepts of quantitative pharmacology. J Pharmacol Exp Ther 320:1-13. 
Vergara R, Rick C, Hernández-López S, Laville JA, Guzman JN, Galarraga E, Surmeier DJ, Bargas J (2003) Spontaneous voltage oscillations in striatal projection neurons in a rat corticostriatal slice. J Physiol 553:169-182.

Wang M, Vijayraghavan S, Goldman-Rakic PS (2004) Selective D2 receptor actions on the functional circuitry of working memory. Science 303:853-856.

Wang Y, Goldman-Rakic PS (2004) D2 receptor regulation of synaptic burst firing in prefrontal cortical pyramidal neurons. Proc Natl Acad Sci U S A 101:5093-5098.

Wang Y, Markram H, Goodman PH, Berger TK, Ma J, Goldman-Rakic PS (2006) Heterogeneity in the pyramidal network of the medial prefrontal cortex. Nat Neurosci 9:534-542.

Winterer G, Weinberger DR (2004) Genes, dopamine and cortical signalto-noise ratio in schizophrenia. Trends Neurosci 27:683-690.

Yamada K, Ashikari I, Onishi K, Kanba S, Yagi G, Asai M (1995) Effectiveness of nilvadipine in two cases of chronic schizophrenia. Psychiatry Clin Neurosci 49:237-238.

Yamada K, Kanba S, Ashikari I, Ohnishi K, Yagi G, Asai M (1996) Nilvad- ipine is effective for chronic schizophrenia in a double-blind placebocontrolled study. off. J Clin Psychopharmacol 16:437-439.

Yizhar O, Fenno LE, Prigge M, Schneider F, Davidson TJ, O'Shea DJ, Sohal VS, Goshen I, Finkelstein J, Paz JT, Stehfest K, Fudim R, Ramakrishnan C, Huguenard JR, Hegemann P, Deisseroth K (2011) Neocortical excitation/inhibition balance in information processing and social dysfunction. Nature 477:171-178.

Yoon DY, Gause CD, Leckman JF, Singer HS (2007) Frontal dopaminergic abnormality in Tourette syndrome: a postmortem analysis. J Neurol Sci 255:50-56.

Young CE, Yang CR (2004) Dopamine D1/D5 receptor modulates statedependent switching of soma-dendritic $\mathrm{Ca} 2+$ potentials via differential protein kinase $\mathrm{A}$ and $\mathrm{C}$ activation in rat prefrontal cortical neurons. J Neurosci 24:8-23.

Zhang Y, Bertolino A, Fazio L, Blasi G, Rampino A, Romano R, Lee ML, Xiao T, Papp A, Wang D, Sadée W (2007) Polymorphisms in human dopamine D2 receptor gene affect gene expression, splicing, and neuronal activity during working memory. Proc Natl Acad Sci U S A 104:20552-20557. 